\title{
Quality of Government and Types of Innovation-Empirical Evidence for Italian Manufacturing Firms
}

\author{
Cristian Barra ${ }^{1} \cdot$ Nazzareno Ruggiero $^{1}$
}

Received: 10 November 2020 / Accepted: 23 January 2022

(c) The Author(s) 2022

\begin{abstract}
Using firm-level information on Italian manufacturing companies provided by Capitalia and the Institutional Quality Index (IQI) dataset over the 2004-2006 (10th edition) period, we employ a multi-probit model to assess the effects of government quality upon four dimensions of innovation, namely, marketing, organisational, product and process innovation. Findings presented in the paper suggest that higher government quality stimulates firms' innovative activities, though the impact of governance varies across the various dimensions of innovation examined. Our evidence, which is robust to firms' size, PAVITT classification and firms' geographical location, provides room for policy interventions.
\end{abstract}

Keywords Quality of government · Innovation · Manufacturing firms ·

Manufacturing industries · Firms' size

JEL Codes $\mathrm{D} 22 \cdot \mathrm{O} 3 \cdot \mathrm{R} 1 \cdot \mathrm{L} 6 \cdot \mathrm{L} 11$

\section{Introduction}

According to North (1991, page 97), "Institutions are humanly devised constraints that structure political, economic and social interaction", implying that both formal and informal institutions shape individual incentives and define, jointly with income, the limits of human behaviour.

Efficiently designed institutions reduce both the transaction costs and the uncertainty in exchange which usually characterises the interactions between

Cristian Barra

cbarra@unisa.it

Nazzareno Ruggiero

nruggiero@unisa.it

1 Department of Economics and Statistics (DISES), University of Salerno, Viale Giovanni Paolo II, 132, 84084 Fisciano, Italy 
uncoordinated agents who have incomplete information. It turns out that institutions play a key role in maximising the gains from trade and increasing productivity. The design of an efficient institutional environment and its evolution over time are therefore fundamental in explaining both the stages of development and the economic performances of countries (Boettke \& Fink, 2011; Myrdal, 1957; North, 1994).

The beneficial effects of increased institutional quality on long-run growth have been largely documented in the literature (Hall \& Jones, 1999; Acemoglu et al., 2001; Dollar \& Kraay, 2003; Acemoglu et al., 2005, Acemoglu \& Robinson, 2010). According to these papers, the observed diverging patterns in the levels of per-capita income across countries are essentially caused by differences in the efficiency of the institutional system and in the ability of the latter to protect and efficiently define property rights.

The advent of the endogenous growth theory has instead highlighted the relevance of the technological progress as main source of economic growth (Aghion \& Howitt, 1992, 2007; Aghion et al., 2016; Lucas, 1988; Romer, 1990).

Given the strong existing linkages between growth, institutions and technological development, a large amount of literature has been devoted to the analysis of the effects of institutions on innovation. The theoretical literature, see for instance Immordino et al. (2011) and Anderlini et al. (2013), has investigated the institutional conditions under which the level of R\&D investments is socially efficient. Specifically, Immordino et al. (2011) propose a theoretical framework based on four institutional regimes, namely, laissez-faire, ex-post penalties, lenient authorisation and strict authorisation. They show that laissez-faire is the optimal regime provided that the probability of social harm from innovation is small, while ex-post penalties and lenient authorisation should be imposed for moderate likelihoods of social harm from $R \& D$ investments. Strict authorisation is instead the optimal institutional regime when the probability of social harm from investments is high. Anderlini et al. (2013) develop a theoretical model aimed at assessing the effects of legal institutions on innovation, partitioning the legal system in rigid, where the set of rules is determined before technological progress takes place, and flexible, where rules are defined once the technology is observed. They show that the flexible regime maximises innovation, welfare and output growth at intermediate levels of development, while at its early stages a rigid system must be preferred because of commitment issues. While the theoretical literature has tried to identify the institutional and legal conditions under which innovation is socially optimal, a significant amount of empirical research has instead been devoted to the analysis of the effects of corruption and political stability on innovation. Examples of such a vast literature are the contributions of Anokhin and Schulze (2009), Aghion et al. (2016), Ervits and Zmuda (2018), Dincer (2019), Ellis et al. (2019) and Lee et al. (2020), which provide favourable evidence for the "sanding the wheels" hypothesis, as corruption has a negative impact on innovation, with innovative firms that are disproportionally more victims of corruption compared to their non-innovative counterparts (Ayyagari et al., 2014). Paunov (2016) documents a non-significant effect on corruption on patents, though she finds that higher corruption has a detrimental effect on the likelihood of obtaining quality certificates and reduces the demand of machineries and other inputs which are complementary to innovation processes. 
According to these papers, the monopoly power of corrupted bureaucrats can be tough of as a tax on innovators, which, in turn, decreases the expected gains of innovative projects, hence preventing firms from investing in innovative activities.

Another strand of the literature has instead dealt with the relationship between political stability and innovation (Alesina \& Perotti, 1996; Waguespack et al., 2005; Hoti \& McAleer, 2006; Allard et al., 2012; Gholipur, 2019), the general consensus being that higher political instability, increasing the likelihood of coups through unconstitutional means, heightens the risk of expropriation and reduces the trust in the courts and in the rule of law, therefore discouraging firms from undertaking innovative projects.

More closely related to the following paper, at least with respect to the measures of government quality employed, are the contributions of Tebaldi and Elmslie (2013), Rodríguez-Pose and Di Cataldo (2015), Oluwatobi et al. (2015), Kwan and Chiu (2015), Alam et al. (2019) and Rodríguez-Pose and Zhang (2020), which rely on various indices of governmental quality, such as risk of expropriation, control of corruption, rule of law, regulatory quality, government effectiveness, voice and accountability, with unanimous consensus in ascertaining a positive effect of governance upon firms' investment decisions.

The six pillars of governance proposed by the World Bank, i.e. control of corruption, government effectiveness, rule of law, political stability, regulatory quality and voice and accountability, (see Kaufmann et al., 2010) have instead been applied in the contributions of Giménez and Sanaú (2007), Soumaré and Tchana Tchana (2015), Asongu et al. (2018), Cahn et al. (2019) and Clò et al. (2020), which provide additional evidence of a positive relationship between improved institutional quality and innovation.

This literature further identifies the main channels through which the quality of government can affect innovative activities. Firstly, however, it must be highlighted that R\&D investments are risky and characterised by a significant uncertainty concerning their outcome (see for instance Esposti \& Pierani, 2003; Dewett, 2007; Muscio \& Ciffolilli, 2020), with the implication that the uncertainty related to R\&D innovation might be exacerbated by the presence of weak and unstable institutions. In particular, the presence of effective governments and efficient rule of law respectively allow to implement credible long-term innovative policies and to strengthen intellectual property rights, enhancing R\&D activities (Rodríguez-Pose \& Di Cataldo, 2015). Higher voice and accountability, according to Faust (2008), limits the power of narrow interest groups and promotes a favourable business environment, hence encouraging innovation. According to Waguespack et al. (2005), higher political stability is beneficial to $R \& D$ activities as it reduces the uncertainty related to the appropriability of innovation and reduces the risk of expropriation, while following the lines of Ayyagari et al. (2014), it can be argued that higher control of corruption reduces the costs of R\&D and fosters the adoption of new technologies. Finally, a stable regulatory discourages corruption among bureaucrats (Lee et al., 2020) and promotes science-oriented educational systems (Varsakelis, 2006).

Though the main literature agrees in ascertaining that countries with better governance display a higher propensity to undertake innovative activities, one limitation of these contributions is represented by the fact that they deal with a single 
dimension of innovation, summarised by the amount of patents issued, while other relevant dimensions have been largely neglected. Examples of this limited literature include the paper of Sobel (2008), De Waldemar (2012), Jiao et al. (2015), Castellucci (2015) and Barasa et al. (2017). Specifically, Sobel (2008) studies the effects of institutional quality on entrepreneurial activities, finding, in line with Baumol's hypothesis, that better governance spurs entrepreneurship and growth, while De Waldemar (2012) investigates the effects of corruption on product innovation, showing that increased corruption discourages the introduction of new products in the market. Jiao et al. (2015) instead address the role of government effectiveness on technological innovation, process innovation and managerial innovation, finding evidence of a positive relationship between the efficiency of the government in providing public services and all the afore-mentioned dimensions of innovation. Castellucci (2015) deals with the impact of legal, financial and institutional constraints using data for 20 Latin American countries, finding that the innovative performance of firms is better in those countries with a better governance and with less institutional constraints. Similar results are obtained by Barasa et al. (2017), who exploit data for Kenya, Tanzania and Uganda, to examine the nexus between regional governance and product innovation, showing that the propensity to innovate is positively affected by a healthier institutional environment. Differently from these contributions, in this paper, combining firm-level data collected by Capitalia and the Institutional Quality Index (IQI) dataset developed by Nifo and Vecchione (2014) at provincial level (NUTS3), we test the effects of government quality on additional dimensions of innovation, namely, marketing innovation, organisational innovation, product innovation and process innovation, whose relevance has largely been highlighted in the literature. Indeed, according to Cohen and Klepper (1996), product and process innovation are fundamental for firms as they allow them to spread the price-cost margin of the output sold. Further, while product innovation is intended to increase the price of goods, process innovation allows firms to reduce the average cost of production. Organisational innovation is instead relevant for firms as, on one side, it facilitates the development of new products and processes (Camisón \& Villar-López, 2014) and, on the other, provides firms with a competitive advantage by affecting their performance and increasing productivity (Caroli \& Van Reenen, 2001). Finally, according to Karlsson and Tavassoli (2016, pp. 1485-1486), marketing innovation allows firms "to give the firm's products a new position in the market with the intention to increase sales incomes". This paper tries to provide an answer to the following research question: How does the quality of government influence different types of innovation of manufacturing firms?

The empirical findings presented here reveal that rule of law is the only governance measures which is found to stimulate marketing activities. Once the focus is on organisational innovation, results suggest that the control of corruption, regulatory quality and voice and accountability positively contribute to this dimension of innovation, while product and process innovation are mostly driven by variations in government effectiveness, regulatory quality and voice and accountability.

The paper is structured as follows: "Data and Variables Selection" section describes the data and the main variables employed to assess the nexus between government quality and the various types of innovation, while "The Empirical 
Specification" section describes the empirical framework. "Empirical Evidence" section discusses the empirical findings, while in "Robustness Checks" section various robustness checks are performed. "Limits of the Analysis" section assesses the main limitations of our contribution, while "Conclusions and Discussions" section concludes and discusses the main policy implications.

\section{Data and Variables Selection}

The survey used to explore firms' innovation dynamics is based on Italian manufacturing companies, originally edited by Mediocredito Centrale, and currently carried out by the Capitalia Banking Group's Research Department. The survey is a fundamental point of reference for politicians, scholars and operators that are interested in the structural and evolutionary characteristics of the Italian industrial system. A key feature of the Observatory database on small- and medium-sized enterprises is the large amount of qualitative information gathered through the administration of a questionnaire divided into six sections (for more details see the questionnaire distributed by Capitalia).

Unfortunately, as information on firms' innovation and other relevant variables employed in the paper is no longer available beyond 2006, the analysis is built on one wave, which covers the 2004-2006 (10th edition) period. In line with other studies based on the same data source (Hall et al., 2013; Maietta, 2015), the survey design includes all firms with at least 500 workers and a sample that is representative of Italian manufacturing firms that employ between 10 and 500 workers and that is stratified by firm size, industrial sector and geographical area. Firms are asked whether process, product and/or other innovations were introduced during the previous 3 years. The questionnaire also collects information regarding firms' characteristics, such as the presence of skilled employees (that is graduates) and the amount of R\&D expenditures. Moreover, qualitative information and balance sheet ratios are classified according to sectors of technological activity (see PAVITT classification in footnote 5, "How Does Territorial Diversification Affect the Estimates?" section) and by macro-regions (North-West, North-East, Centre and South-Islands).

The sampling design is based on a three-dimension stratification: industry or class of activity (11 NACE-CLIO codes), region (NUTS1 level) and size class (10-19; 20-49; 50-99; 100-249 and more than 250 employees). The questionnaire also provides information concerning the relevant sources of $R \& D$, as it collects information on whether R\&D was acquired from external sources such as universities/research labs and other firms/consultants. Other relevant information includes the amount of R\&D expenditures (our proxy of knowledge capital) and whether firms receive tax allowances and financial incentives for their R\&D intensity. Size classes have been used with respect to the number of employees, along with other firms' characteristics, such as the presence of skilled employees, age of the firm and its current legal form (cooperatives vs no cooperatives).

To appraise the impact of government quality on innovation, Capitalia statistics have been combined with the Institutional Quality Index (IQI) dataset proposed by Nifo and Vecchione (2014), extracted at provincial level, which provides, over the 2004-2012 period, information for the following dimensions of government 
quality": (a) control of corruption: "summarizes data on a crimes committed against the Public Administration (PA), the number of local administrations overruled by the federal authorities and the Golden-Picci Index, measuring the corruption level on the basis of 'the difference between the amounts of physically existing public infrastructure (...) and the amounts of money cumulatively allocated by government to create these public works' (Golden \& Picci, 2005, page 37)" (Nifo \& Vecchione, 2014 page 1633); (b) government effectiveness: "measures the endowment of social and economic structures in Italian provinces and the administrative capacity of provincial and regional governments in relation to policies concerning health, waste management and the environment" (Nifo \& Vecchione, 2014 page 1633); (c) rule of law: "summarizes data on crime against persons or property, on magistrate productivity, trial times, the degree of tax evasion and the shadow economy" (Nifo \& Vecchione, 2014 page 1633); (d) regulatory quality: "comprises information concerning the degree of openness of the economy, business environment and, hence, the ability of local administrators to promote and protect business activity" (Nifo \& Vecchione, 2014 page 1633) and (e) voice and accountability: "captures the participation in public elections, the phenomenon of associations, the number of social cooperatives and cultural liveliness measured in terms of books published and purchased in bookshops" (Nifo \& Vecchione, 2014 page 1633). To obtain an overall index of government quality, Nifo and Vecchione (2014) have therefore aggregated the afore-mentioned dimensions of governance within the IQI indicator. The construction of the IQI consists of three alternative phases, namely, normalisation, weight assignment and aggregation. With respect to normalisation, this initial procedure is carried out by considering the distance from an ideal point, which allows to obtain scores in the $[0,1]$ interval. The assignment of the weights follows instead the approach of Saaty $(1980,1992)$ and is based on the analytic hierarchy process (AHP). The scores obtained in the first two phases are then aggregated to obtain the IQI indicator. The dataset, inspired along the lines of the World Bank Governance Indicators (WBGI) developed by Kaufmann et al. (2010), relies of various institutional and administrative sources to provide comparable scores of government quality within Italian provinces. ${ }^{2}$ As stated before, each score lies in the range $[0,1]$, with higher scores being associated to higher quality of government.

Table 1 describes the variables employed in the empirical analysis and the main descriptive statistics. According to Table 1, among all firms in the sample, $50 \%$ have introduced product innovation, while $43 \%$ declared the introduction of process innovation. A higher presence of product rather than process innovation may be explained by the industry product direction (Furtan \& Sauer, 2008), by the presence of protected designation of origin and traditional specialty guaranteed trademarks (Mancini \& Consiglieri, 2016) and, probably, by firms' strategies

\footnotetext{
1 As the information provided by Capitalia is available only covers the 2004-2006, data from Nifo and Vecchione (2014) refer to the same time span, implying that information after 2006 is not included in our final dataset.

${ }^{2}$ For additional details, please refer to Nifo and Vecchione (2014).
} 


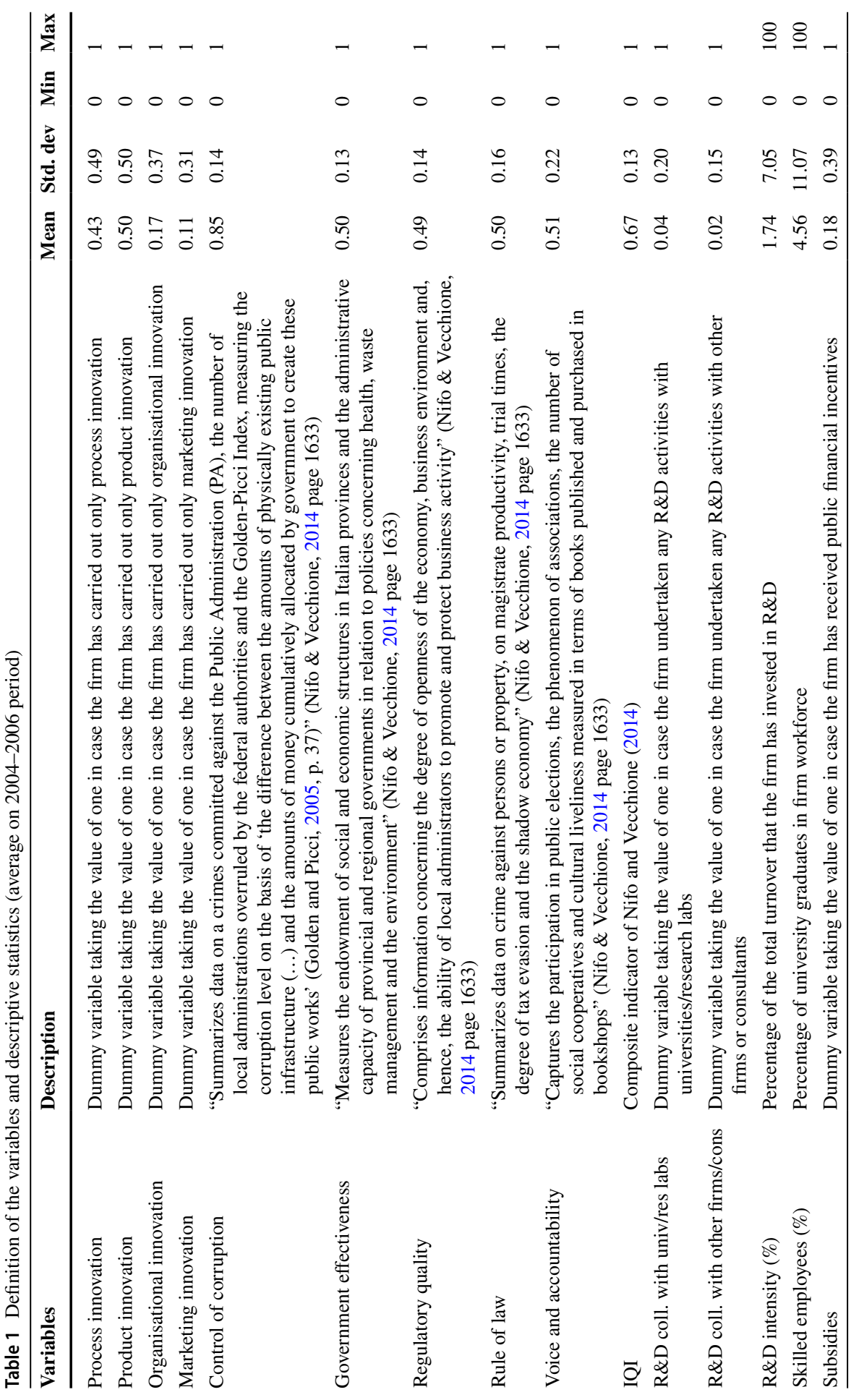




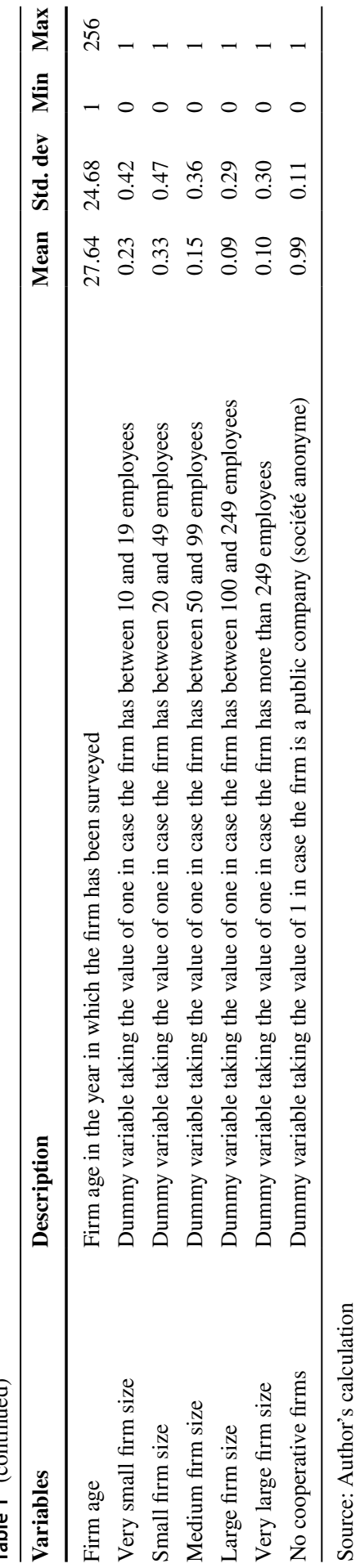


aimed at increasing the price of goods rather than cutting average costs (Cohen \& Klepper, 1996). Almost $17 \%$ of the firms have adopted organisational innovation while around $11 \%$ of the firms have, instead, introduced marketing-related innovation. The lower propensity in investing in marketing and organisational innovation is probably driven by the nature and the structure of the Italian industrial system, which is largely made of small and medium firms (SMEs), managed at the family level. Almost $4 \%$ of the firms in our sample have developed R\&D collaborations with a university or research labs, while the share of those that have stipulated R\&D collaborations with other firms or consultants is almost $2 \%$. R\&D intensity, i.e. the percentage of the total turnover invested in R\&D by the firm, is, on average, $1.74 \%$. Eighteen percent of the firms have received public subsidies and $5 \%$ rely on a skilled labour force. Over the total, $22 \%$ of the firms are very small, $33 \%$ as small and $15 \%$ as medium. Large and very large firms, on the other hand, respectively amount for $9 \%$ and $10 \%$ of the firms in our sample. The average age of the firm is instead 27.64 years, while virtually all the firms available in our sample are legally classified as non-cooperatives.

With respect to the set of government quality variables employed in the paper, descriptive statistics reported in Table 1 highlight that, over the period considered, Italy has exerted a consistent effort in fighting corruption, as the average of the estimated score (0.85) is largely higher compared to all the other measures considered. Voice and accountability signals the second best performance among the set of institutional factors, with an estimated average of 0.67 , followed by rule of law and government effectiveness (both 0.50 ) and regulatory quality (0.49). To assess the characteristics and the territorial distribution of both innovation and government quality, Figs. 1 and 2 provide provincial-level information on the relevant measures of innovation and institutional quality employed in the paper.

With respect to the distribution of the main dimensions of innovation considered in the paper, Fig. 1 reveals a prevalence of both product and process innovation compared to marketing and organisational innovation. Moreover, provincial-level information reported in Fig. 1 signals a clear dualism in terms of firms' performance within the national territory, with firms operating in Centre and Northern provinces which significantly outperform the ones operating in the South in terms of all the dimensions of innovation examined. In particular, according to our data, less than 10 Southern provinces out of 36 range in the highest modal class.

A similar picture emerges once we focus on the provincial-level quality of government where, according to the statistics reported in Fig. 1, out of the five dimensions of governance quality considered, in four of them no Southern province ranges in the top of the distribution, with one exception in the case of regulatory quality, where, however, only one province over 36 lies in the highest modal class. The composite indicator of government quality, i.e. the IQI index of Nifo and Vecchione (2014), confirms that the overall quality of government is significantly larger in Northern provinces and lower in the Southern ones. All in all, the evidence reported in Figs. 1 and 2 reveals a marked dualism in terms of both innovative performance and the quality of government between peripheral Southern provinces and the core provinces of the country. 


\section{Marketing Innovation}

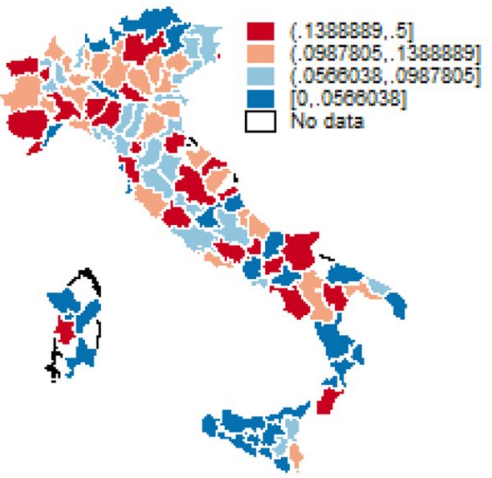

\section{Product Innovation}

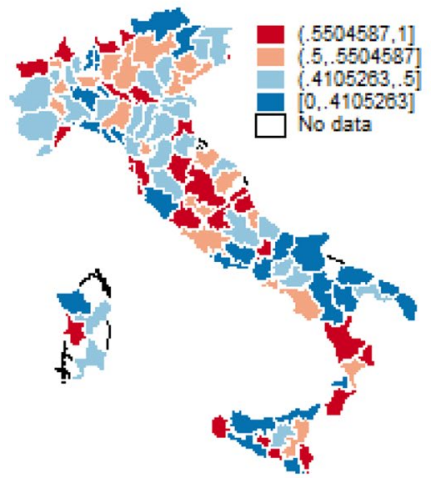

Organisational Innovation

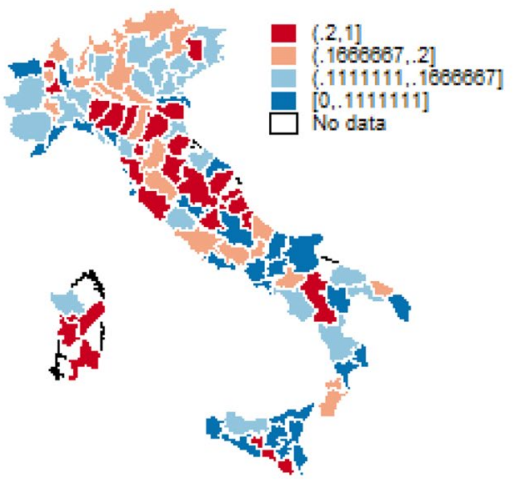

\section{Process Innovation}

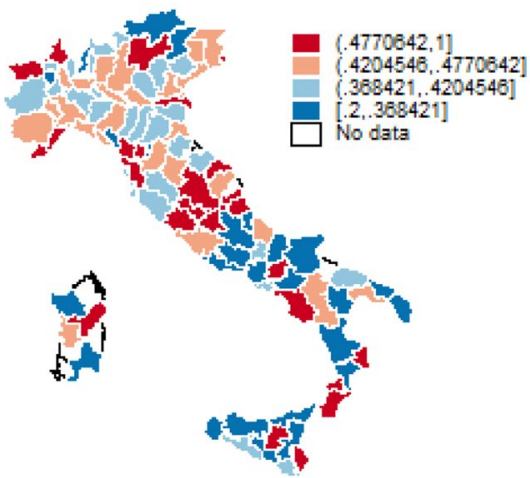

Fig. 1 Innovation in Italian provinces. Source: Authors' elaborations from Capitalia database (20042006 period)

Table 2 reports the Pearson's correlation coefficients of the main variables of interest. Pairwise correlations suggest that the different dimensions of innovation considered in the paper are significantly correlated with R\&D intensity and with collaborations with universities' centres and other firms. Moreover, according to Table 2, the relevant dimensions of innovation examined are strongly interconnected, as suggested by the positive and significant sign of the estimated correlations. With respect to the role of government quality, the composite indicator of Nifo and Vecchione (2014) positively correlates with all the various dimensions of innovation. Increased control of corruption is found to positively influence marketing and organisational innovation, while government effectiveness is shown to be positively correlated with product innovation. Regulatory quality exhibits a positive and significant linear correlation with all the dimensions of innovation but process innovation, while the opposite holds for rule of law, whose correlations with the main measures of innovation are found to be not statistically significant. Finally, 

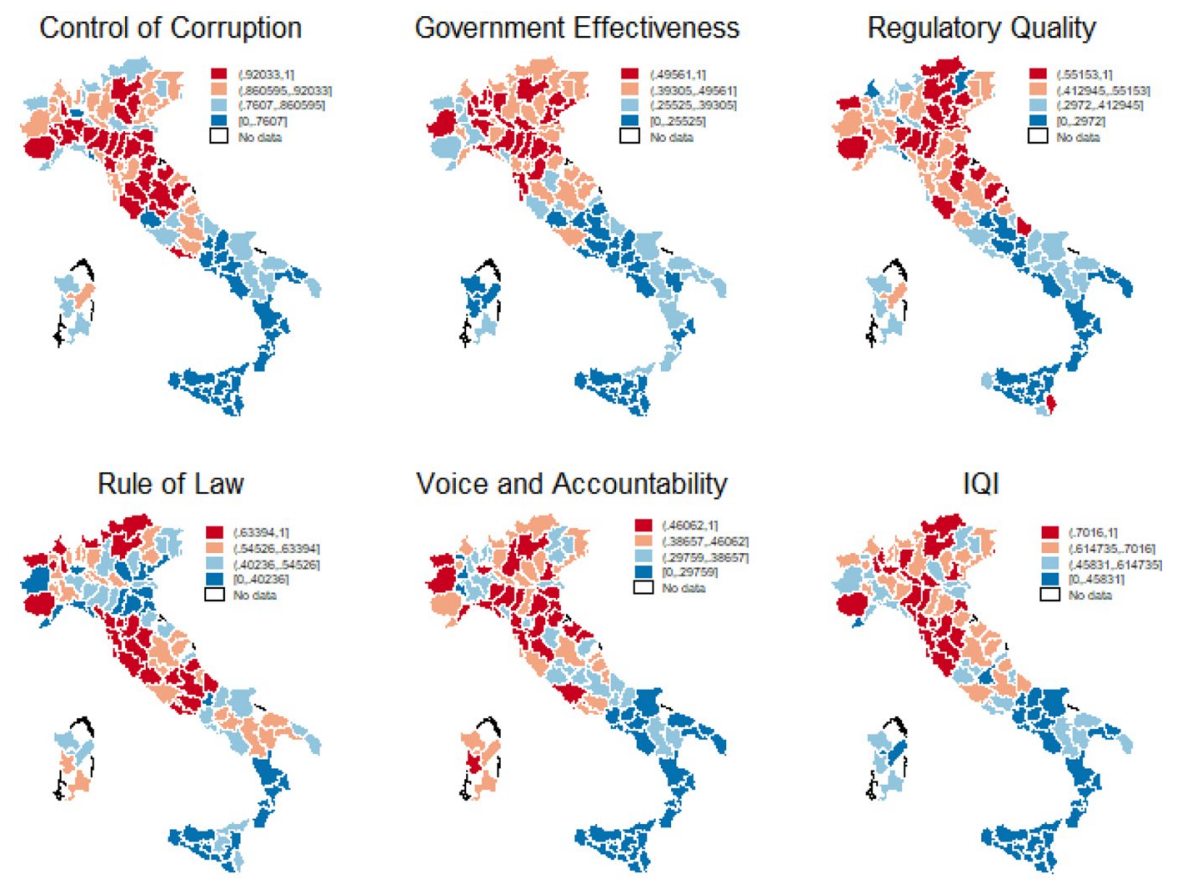

Fig. 2 Government quality in Italian provinces. Source: Authors' elaborations on Nifo and Vecchione (2014) database (2004-2006 period)

voice and accountability is found to be positively correlated with both product and organisational innovation.

\section{The Empirical Specification}

To assess the impact of government quality upon innovation, we propose the following four-equation model, described in Eqs. (1-4):

Innovation $j=f_{j}$ (quality of government indicators, $\mathrm{R} \& \mathrm{D}$ collaboration with universities/research labs, R\&D collaboration with private firms/consultants, R\&D intensity, public subsidies, skilled employees, firm age, firm size dummies, firm legal form dummies, industrial sector dummies, macro-area dummies), where $j=$ marketing, organisational, product, process.

Further, the variance inflation factor (VIF) has been computed to assess multicollinearity among regressors.

The analysis is therefore performed on a sample which includes all firms with at least 500 workers and a sample that is representative of Italian manufacturing firms that employ between 10 and 500 workers. As noted in previous studies which have employed the same data source, see for instance Medda et al. (2006), the sample of Mediocredito is representative of the Italian manufacturing sector as the firms included in the sample represent a large portion of economic activity in the sector. 


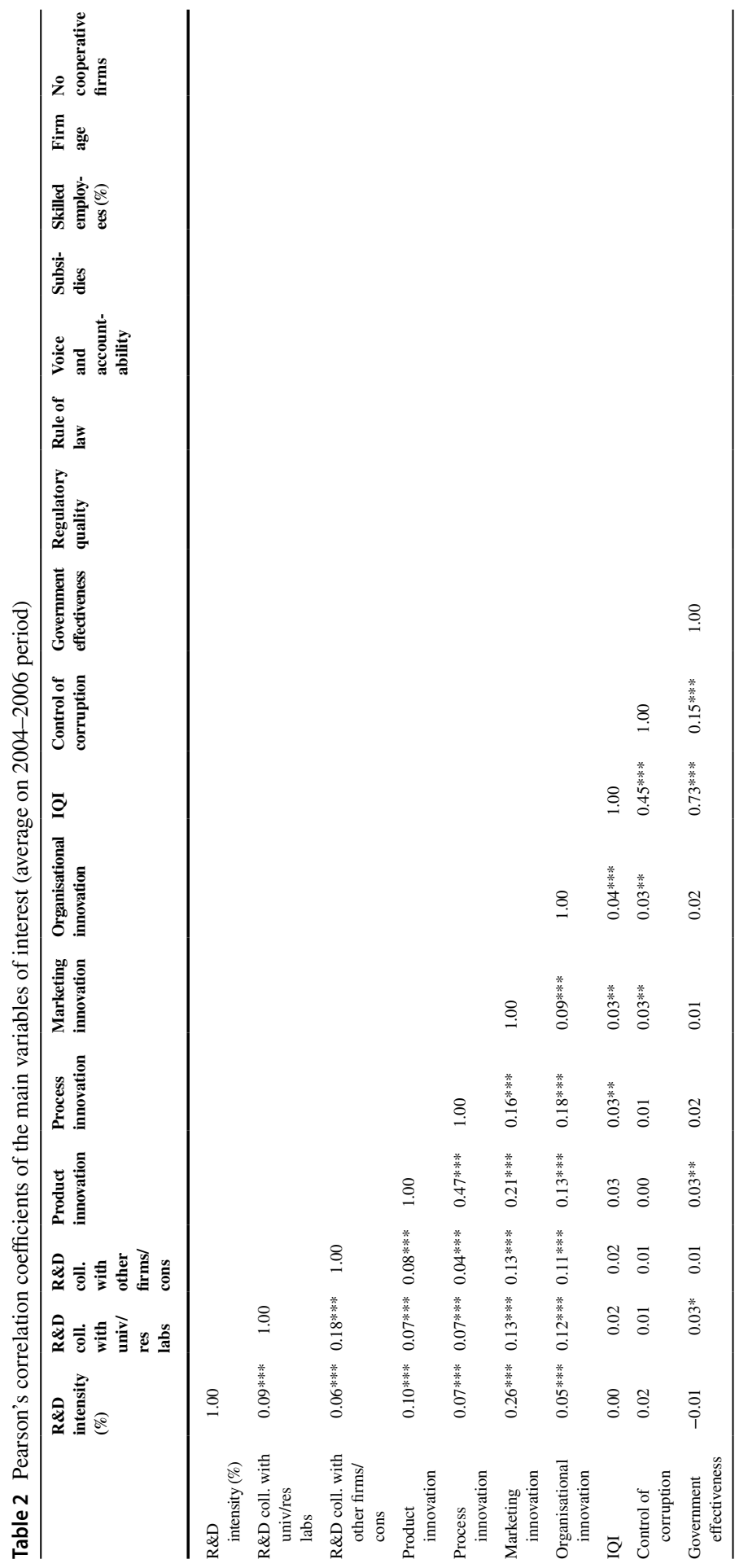




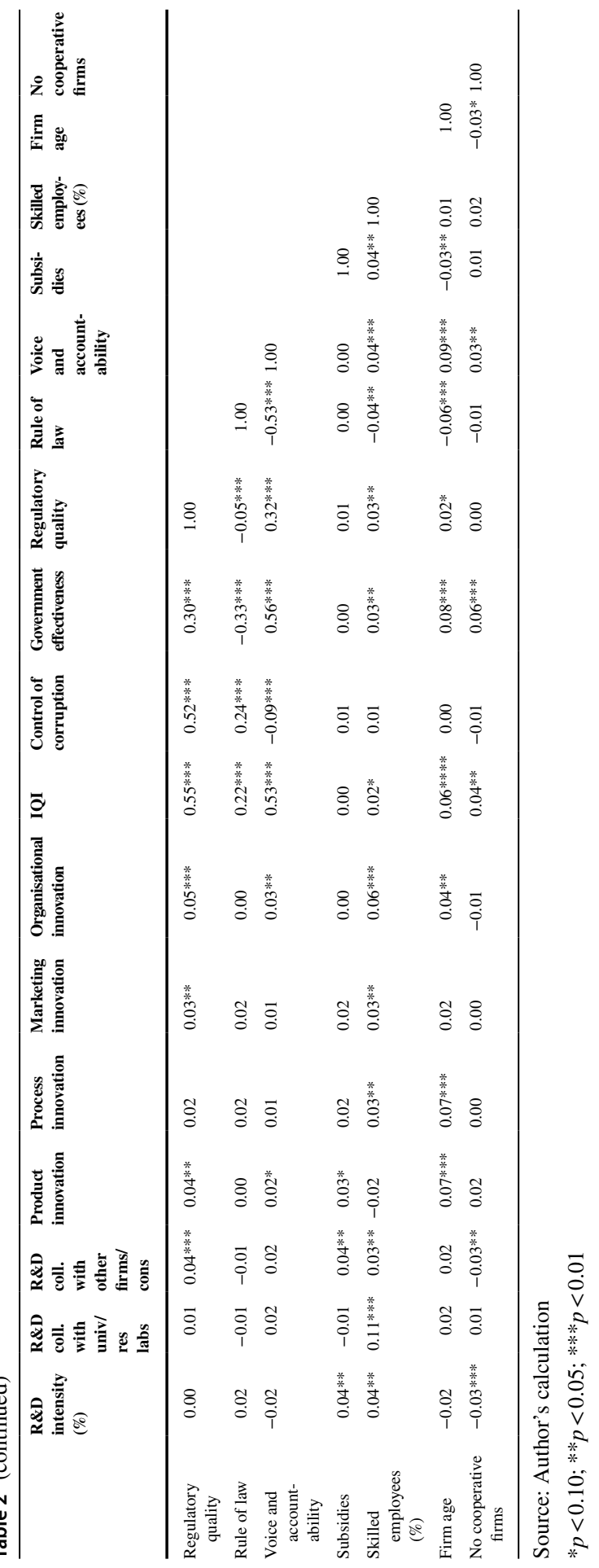


Our final dataset contains information for a set of 5137 firms, geographically distributed as follows: 608 belong to the South-Islands macro-region, 2203 to NorthWestern, 1492 to North-Eastern and, finally, 834 belonging to Central regions.

\section{Empirical Strategy: a Multi-probit Analysis}

In order to test the main hypothesis of the paper, we specify an econometric model which consists of four simultaneous equations for the following dependent variables: marketing, organisational, product and process innovation. Given the presence of both observed and unobserved factors, the relevant dependent variables considered in the empirical analysis are also inter-related. Specifically, the four equations specified here represent structural or outcome equations with human capital (but also other production factors, such as physical capital and knowledge capital) and R\&D decisions variables as explanatory factors.

The four indicators are binary variables and are jointly described by a multivariate probit model. The model follows a four-equation structure (for a similar approach see Maietta, 2015; Maietta et al., 2017; Barra et al., 2019):

$$
\left\{\begin{array}{l}
y_{1 i}^{*}=\boldsymbol{q} \boldsymbol{g}_{1 j}^{\prime} \boldsymbol{\alpha}_{1}+\boldsymbol{x}_{1 i}^{\prime} \boldsymbol{\beta}_{1}+\epsilon_{1 i} \\
y_{2 i}^{*}=\boldsymbol{q} \boldsymbol{g}_{2 j}^{\prime} \boldsymbol{\alpha}_{2}+\boldsymbol{x}_{2 i}^{\prime} \boldsymbol{\beta}_{2}+\epsilon_{2 i} \\
y_{3 i}^{*}=\boldsymbol{q} \boldsymbol{g}_{3 j}^{\prime} \boldsymbol{\alpha}_{3}+\boldsymbol{x}_{3 i}^{\prime} \boldsymbol{\beta}_{3}+\epsilon_{3 i} \\
y_{4 i}^{*}=\boldsymbol{q} \boldsymbol{g}_{4 j}^{\prime} \boldsymbol{\alpha}_{4}+\boldsymbol{x}_{4 i}^{\prime} \boldsymbol{\beta}_{4}+\epsilon_{4 i}
\end{array}\right.
$$

The four latent variables are defined as follows: $y_{1}{ }^{*}$ are marketing innovations (Eq. 1); $y_{2}{ }^{*}$ are organisational innovations (Eq. 2); $y_{3}{ }^{*}$ are product innovations (Eq. 3); $y_{4}{ }^{*}$ are process innovations (Eq. 4); $\boldsymbol{q g}_{k j}$ represents the quality of government indicators, assumed to influence the innovation decisions of firm $i$ and expected to increase the probability of undertaking innovative activities ${ }^{3} ; \boldsymbol{x}_{k i}$ are vectors of exogenous variables (see Table 1 for more details about these variables), which influence those probabilities for firm $i ; \boldsymbol{\alpha}_{k}$ and $\boldsymbol{\beta}_{k}$ are unknown parameters to be estimated; while $\varepsilon_{k i}$ are error terms, which are assumed to be jointly normal with the unknown correlation coefficient, $\rho_{k i}$.

The latent variables $y_{k i}{ }^{*}$ are not observed; while the binary variables, $y_{k i}$, are observed and linked to the former according to the following rule:

$$
\left\{\begin{array}{l}
Y_{k i}=1, \text { if } y_{k i}^{*}>0 ; \\
Y_{k i}=0 \text { otherwise; } k=1,2,3,4
\end{array}\right.
$$

The common latent factor structure of the multivariate probit framework allows to contemporaneously correct for the potential sample selection and to control for the

\footnotetext{
3 As the government quality indicators are highly correlated, throughout the paper they are never pooled together in a single regression to avoid multicollinearity. The estimated marginal effects related to all the specifications presented in the paper are available upon request.
} 
potential endogeneity of the R\&D investment decision (Monfardini \& Radice, 2008), with the resulting biprobit model that can be described as an instrumental variable framework for categorical variables and can be estimated by relying on the simulated maximum likelihood method.

This method relies on the Geweke-Hajivassiliour-Keane smooth recursive conditioning simulator (see for instance Geweke (1989), Hajivassiliour and McFadden (1998) and Keane (1994)) and allows to evaluate the multivariate normal distribution, with the simulated probabilities that are unbiased and bounded within the $(0,1)$ interval (Cappellari \& Jenkins, 2003). The equations specified in (1-4) can therefore be estimated separately as single probit model but, as the correlation between error terms is neglected and simultaneity is not taken into account, the estimated coefficients are inefficient. According to Maddala (1983), indeed, only under the assumption of independent error terms $\varepsilon_{k i}$ the above model can be treated as a set of independent equations.

We use a simultaneous multi-equation approach that addresses the endogeneity of $R \& D$ decisions and institutional decisions and the simultaneity of internal and external R\&D investment. Since the dependent variables are ordinal, the simultaneous approach is a multivariate probit model. Our dependent variables reflect the choice of investing in marketing, organisational, product and process innovation. The determinants of firm innovation are those that have been used successfully in preceding studies (e.g. Maietta, 2015) alongside several specifications of variables reflecting the university scientific composition and output.

The estimation of a multivariate probit model with endogenous binary regressors requires some consideration for the identification of the model parameters. Maddala (1983) proposes that the exogenous covariates in the reduced form equations should contain at least one regressor not included in the structural equations but Wilde (2000) shows that no exclusion restrictions on the exogenous variables are required for parameter identification, when there is sufficient variation in the data. This condition is ensured by the assumption that each equation contains at least one varying exogenous regressor, an assumption which is rather weak in economic applications. Given the assumption of joint normality, the multivariate probit model is identified by functional form. Wilde's contribution makes it clear that theoretical identification does not require availability of any additional instruments for the endogenous variables. However, the presence of equation-specific regressors in formally identified models may improve convergence and make the estimation results more robust to distributional misspecifications (Monfardini \& Radice, 2008).

\section{Empirical Evidence}

In this section, we illustrate the empirical findings of our benchmark specifications concerning the effects of government quality on various dimensions of innovation, namely, marketing, organisational, product and process innovation. ${ }^{4}$

\footnotetext{
${ }^{4}$ For the sake of convenience, in the robustness check we only report the coefficients and the standard errors of the government quality indicators.
} 


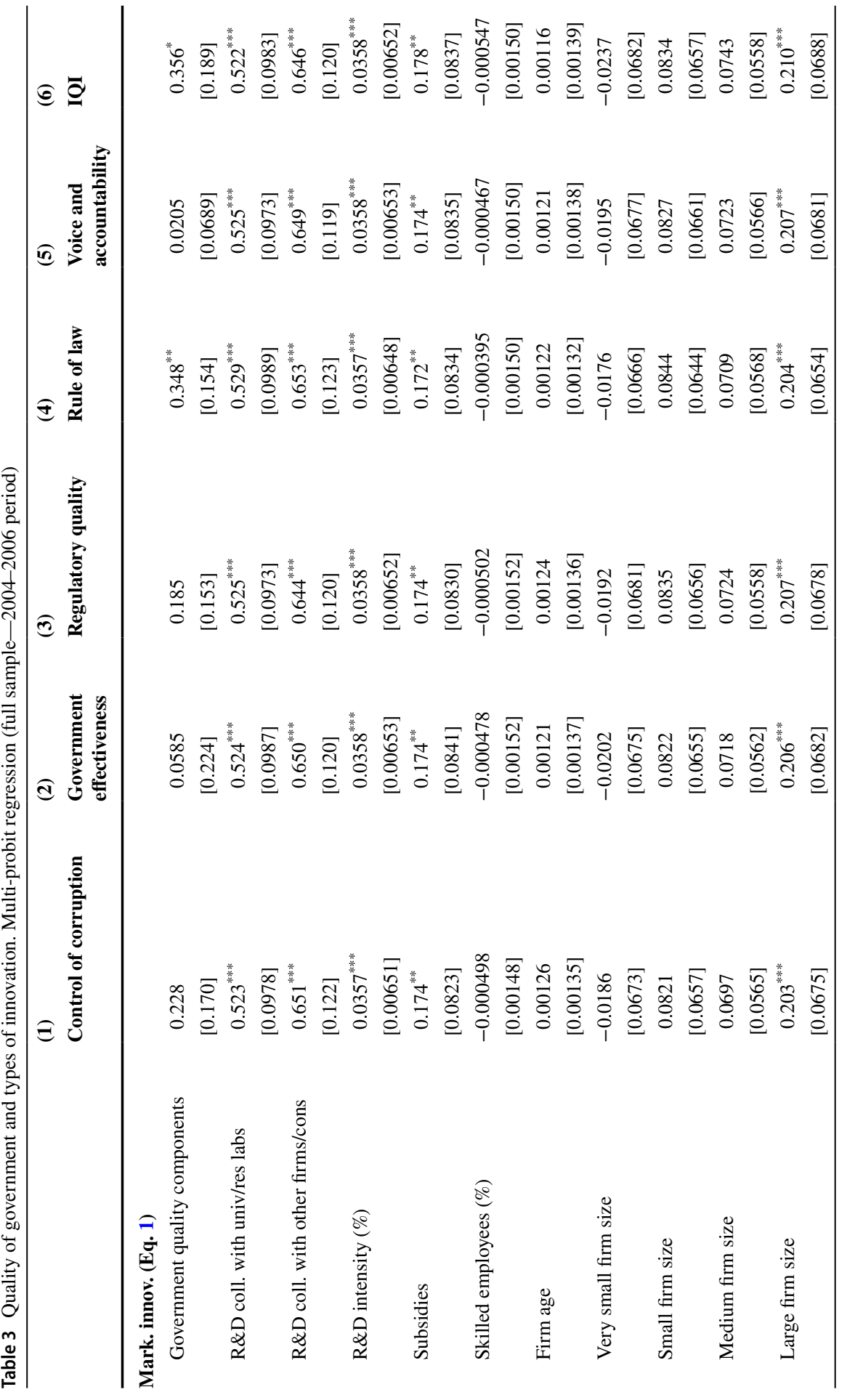




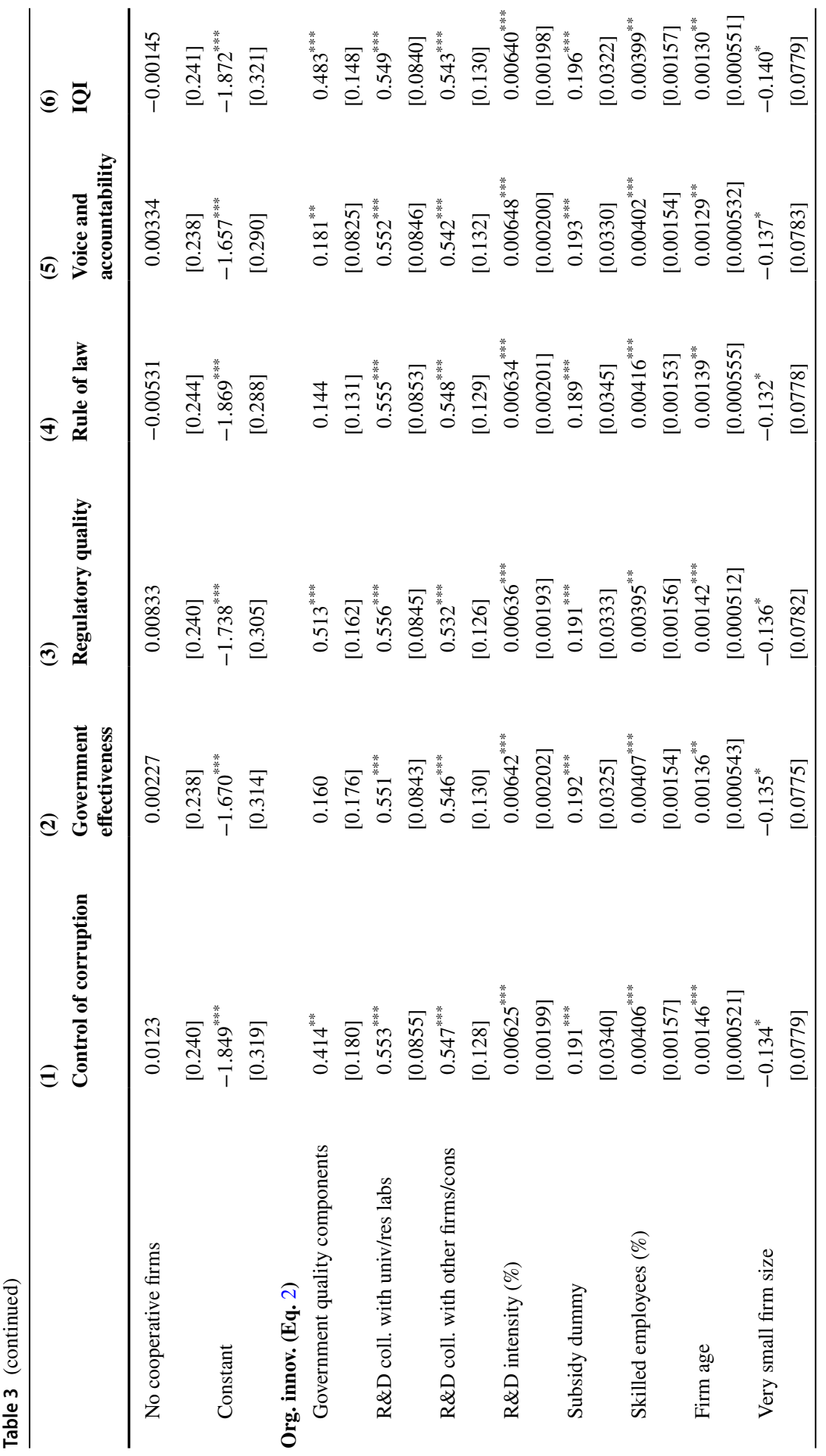




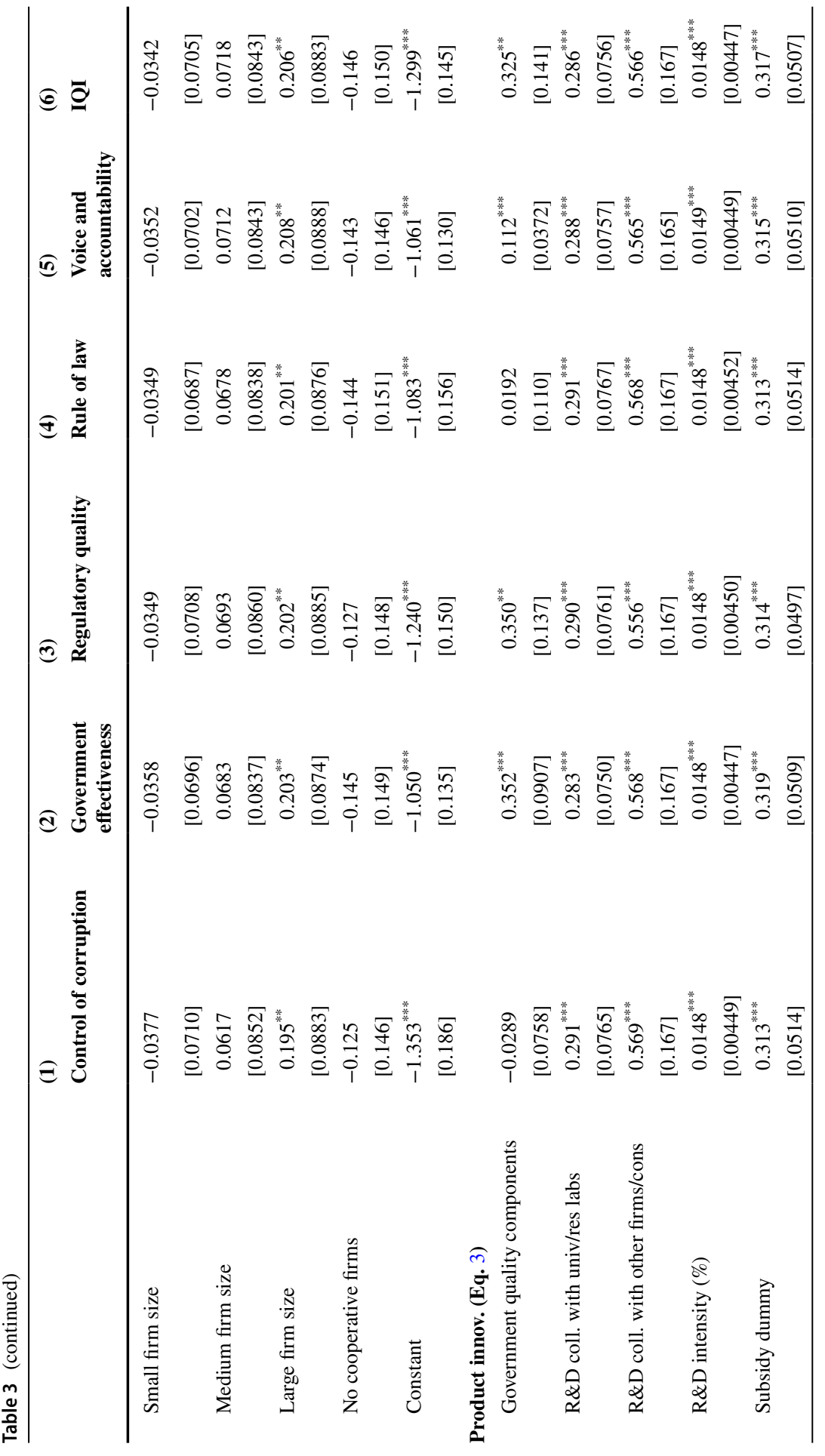




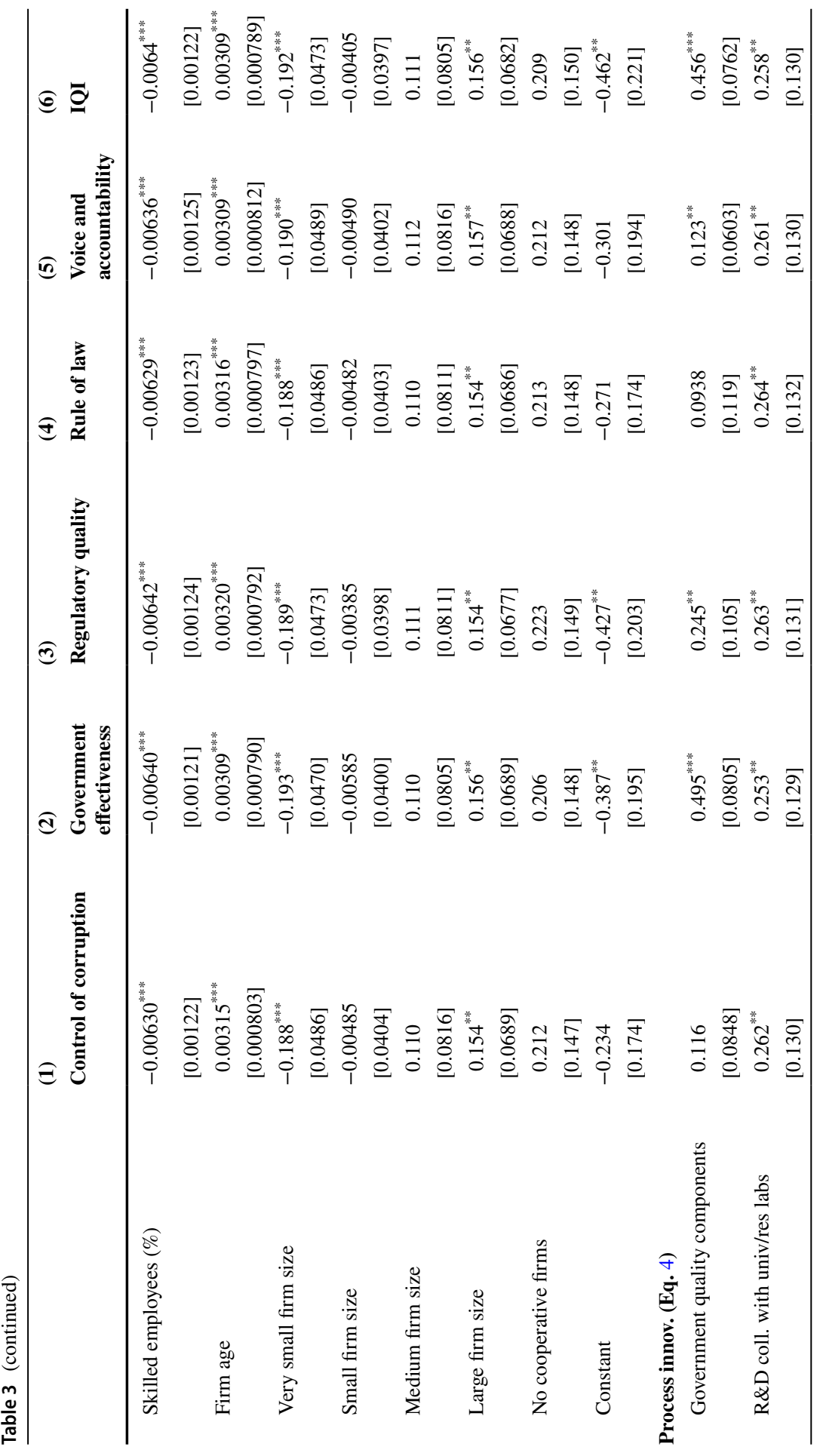




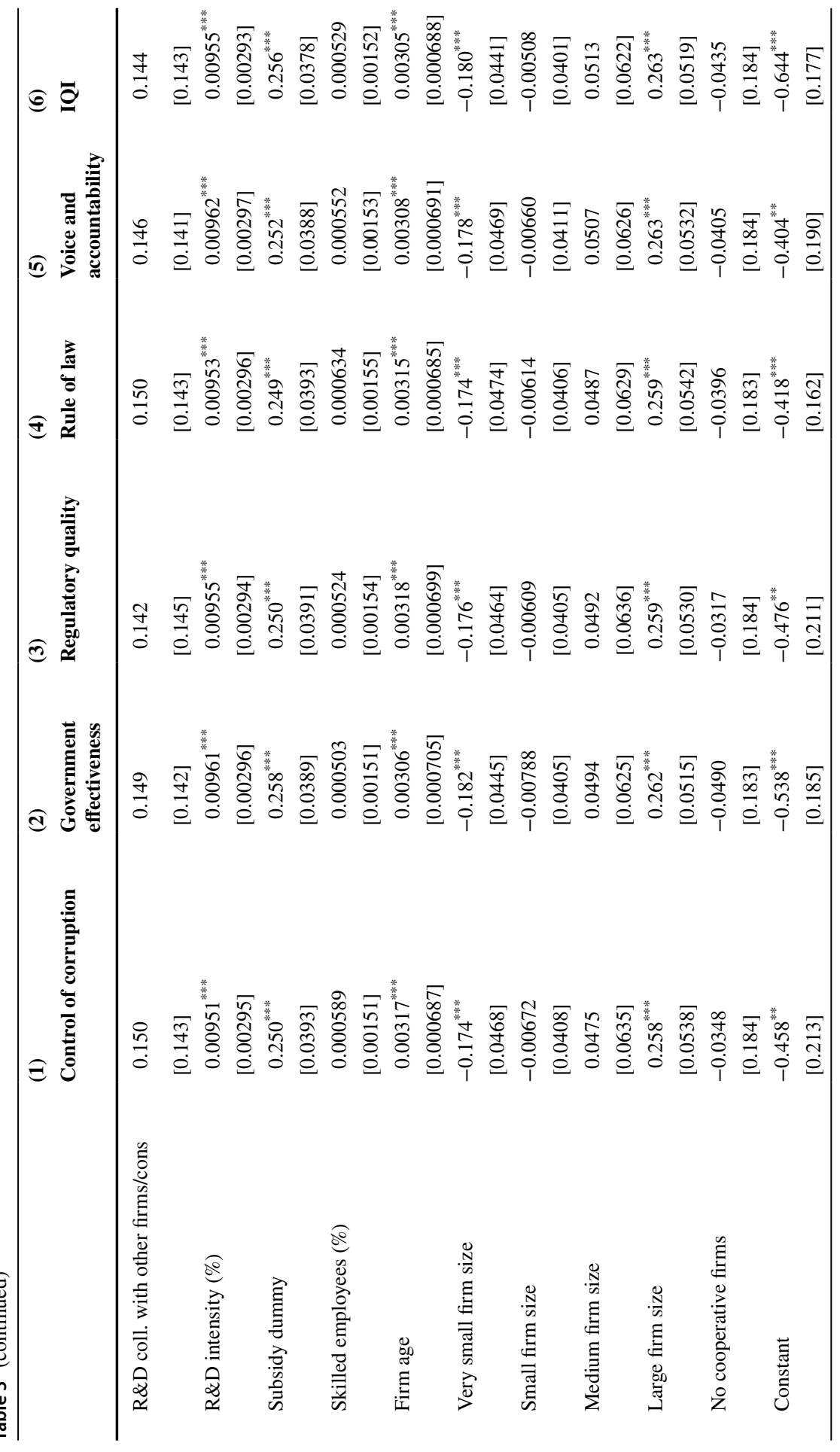




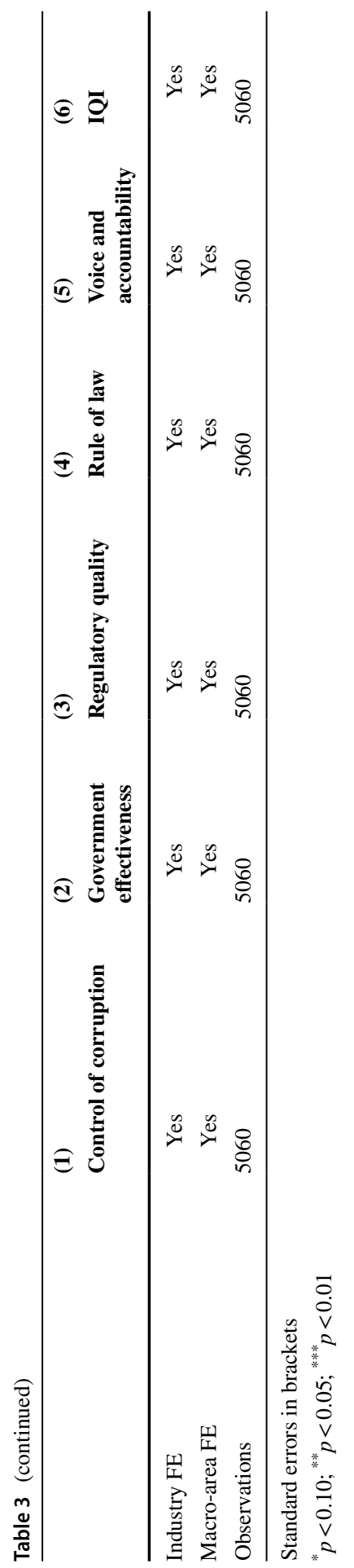


According to Table 3, among the government quality factors considered in our econometric specifications, increased rule of law and the composite indicator are the only measures which are found to stimulate marketing activities. Further, firms that undertake R\&D activities with other firms and with universities' labs are found to be more likely to introduce marketing innovation. A positive and significant relationship is found for R\&D intensity, implying that higher shares of total turnover invested in $R \& D$ have beneficial effects on marketing innovation. Firms that receive financial incentives for their R\&D activities display a higher propensity to invest in marketing innovation compared to those firms that do not receive public incentives. Once we consider firms' size, our findings reveal that large firms have a higher propensity to invest in marketing operations compared to small and medium firms. Once the focus is on organisational innovation, results suggest that the latter is positively affected by increased control of corruption, regulatory quality, voice and accountability and the composite index of government quality.

Findings presented here further reveal that R\&D projects with both universities and firms enhance organisational innovation. Once again, increased turnover invested in R\&D activities has a positive and significant effect on the dimension of innovation considered. Differently from the case of marketing innovation, higher shares of skilled employees stimulate organisational innovation, implying that this dimension of innovation encourages the demand of high-skilled workers. Firms that receive financial incentives for their $R \& D$ activities display a higher propensity to invest in organisational innovation compared to those that do not receive such incentives. Moreover, while aged firms tend to invest more in organisational innovations, the opposite holds true for very small firms, which are less likely to introduce new and more efficient organisational processes.

A similar picture emerges with respect to product innovation, where we find that the probability of introducing new products positively reacts to changes in the quality of government, as shown by the positive and significant coefficients of government effectiveness, regulatory quality, voice and accountability and the aggregate indicator.

Once again, firms that undertake research projects with universities' labs and with other firms are found to be more innovative than firms that do not undertake such collaborations. In line with the previous estimates, firms that are subsidised display a higher likelihood of introducing new products in the market. Nevertheless, we show an inverse and statistically significant relationship between higher proportion of skilled employees and the likelihood of product innovation, a result that signals that the introduction of new products in the market is probably capitalintensive rather than knowledge-intensive, hence discouraging the demand of skilled employees.

We conclude this initial discussion of our empirical results by considering the main determinants of process innovation, which is found to be positively affected by increased government effectiveness, regulatory quality, voice and accountability and by the composite indicator as well, implying that higher quality of the government stimulates process innovation. Differently from the estimates considered so far, collaborations between firms display no significant effect on the probability of process innovation, while firms that are involved in research projects with the academia are 
found to have a higher propensity in introducing new and more efficient processes. In line with the previous estimates, firms that receive financial incentives for their $\mathrm{R} \& \mathrm{D}$ activities and with a higher percentage of turnover invested in R\&D display a higher likelihood of adopting process innovation. The same applies for more aged firms, as the coefficient of this variable is found to be positive, as expected, and highly significant. We further show that very small firms are less likely to invest in innovative projects which involve process innovation, while the opposite holds true for large firms, as the estimated parameters are positive, as one might expect, and highly significant. Findings presented in Table 3, in line with the main literature surveyed in this paper (Barasa et al., 2017; Castellucci, 2015; De Waldemar, 2012; Jiao et al., 2015; Sobel, 2008), confirm that the quality of government plays a key role in stimulating innovative activities, especially those related to organisational, product and process innovation.

\section{Robustness Checks}

This section is devoted to assess the robustness of our benchmark specifications. For our purposes, we provide three alternative robustness checks, respectively based on the partition of firms according to their size, PAVITT classification and geographical location. For the sake of the convenience, we only report the estimated parameters of government quality, while other estimated coefficients are available upon request. We discuss each robustness separately.

\section{How Does Firm Size Affect the Estimates?}

We begin our robustness analysis by reporting estimates of our multi-probit model, when firms are partitioned according to their size, to test whether large and small and medium firms are unevenly affected by the quality of government. The economic literature has indeed shown that the effects of institutional quality on firms' performance crucially depend upon firms' size, with new and small firms that benefit more, compared to large firms, from an improved institutional environment in terms of export performance (LiPuma et al., 2013) and productivity (Agostino et al., 2020). Moreover, according to Paunov (2016), small firms are significantly more hampered by a deteriorating institutional environment, though this contribution only takes into account the effects of corruption, while other dimensions of governance are not explicitly considered. To test to what extent large firms display a higher propensity in undertaking innovative activities and whether the impact of governance is spread asymmetrically across firms' size, we exploit information concerning the number of employees and propose to split the sample into two relevant groups, respectively labelled as large (i.e. those firms with more than 100 employees) and small-medium (i.e. those firms with an amount of employees that ranges between 10 and 100).

Table 4 reports the main results for the group of large firms, i.e. those with more than 100 employees. Findings presented here signal that marketing innovative activities of large firms are not affected by government quality, as the estimated coefficients 


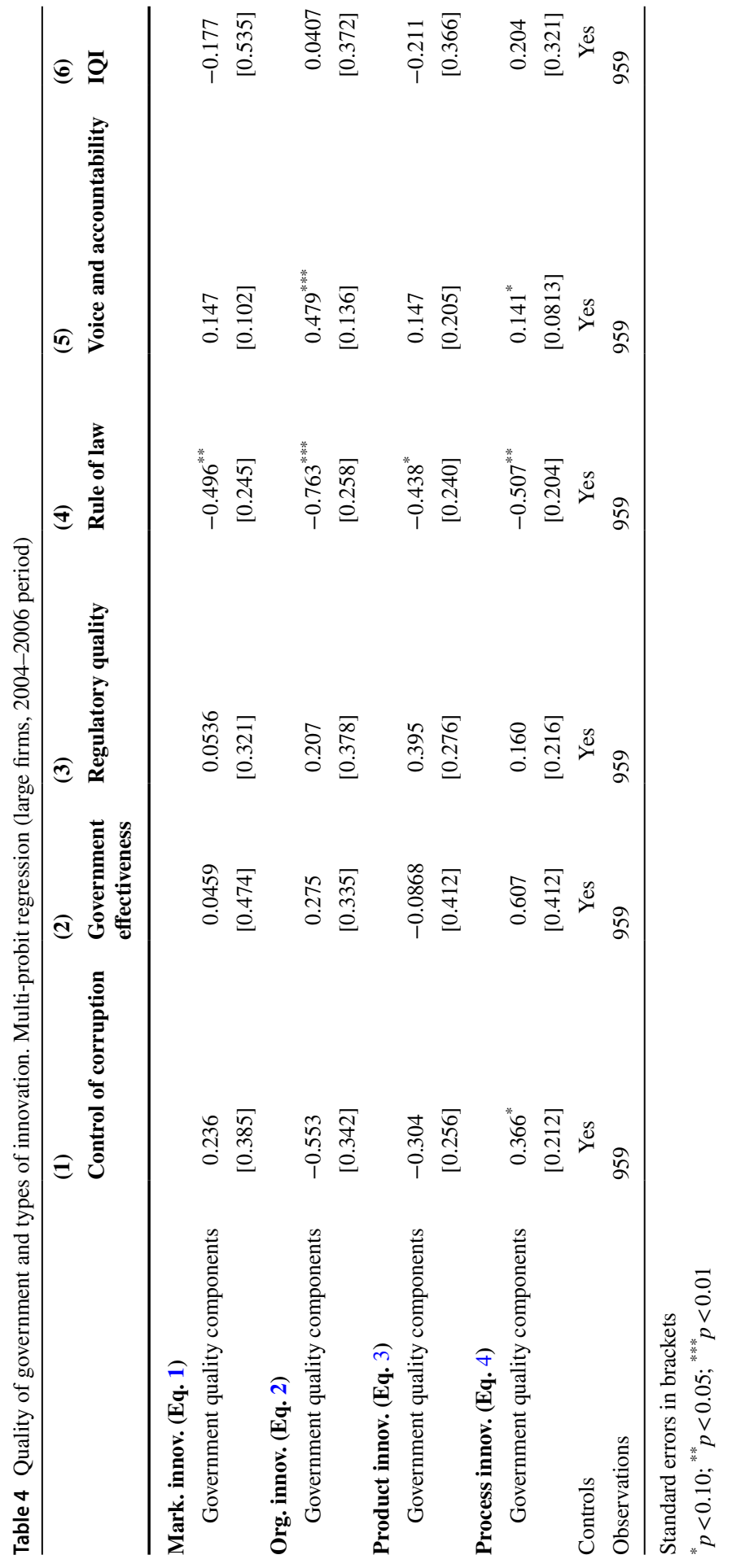


are found to be not statistically significant. Governance quality is instead found to have limited impact upon organisational innovation, as only voice and accountability is found to be significant at $1 \%$ level. In line with the results obtained for marketing innovation, the likelihood of undertaking projects which cause innovation of new products is not driven by changes in the quality of government, as the indices of governance are found to be not statistically significant. We finally consider the nexus between the quality of government and process innovation for large firms. Once this sub-sample is examined, the findings presented here reveal that increased control of corruption, voice and accountability and the composite indicator are the only dimensions of governance which spur the probability of introducing new processes.

One we focus on small and medium firms, evidence reported in Table 5 suggests that the probability of undertaking projects regarding marketing operations is positively affected by improvements in rule of law and in the overall index of governance. Increased control of corruption, higher regulatory quality and the overall index of governance are the three dimensions of government quality that drive organisational innovation. Once we focus on product innovation, the probability of introducing new products in the market is positively affected by variations in government effectiveness, voice and accountability and the composite index, which are found to be positive, as expected, and statistically significant.

We conclude this part of our econometric exercise by focusing on process innovation. Among the set of governance indicators employed in our empirical exercise, only government effectiveness and the composite index of government quality are shown to increase the probability of process innovation. All in all, the evidence reported here, in line with the literature, suggests that small and medium firms would benefit more, compared to large firms, from an improved quality of government.

\section{How Does Technology Affect the Estimates?}

Table 6 reports the results of our proposed multi-probit estimations, partitioning firms according to the PAVITT classification, ${ }^{5}$ to test whether the government quality-innovation nexus is influenced by the industrial sector considered. According to Aldieri et al. (2021), both the rates and the sources of technological innovation

\footnotetext{
5 Pavitt's taxonomy is a classification of the product sectors based on the sources and the nature of technological opportunities and innovations, the intensity of research and development (R\&D intensity), and the type of knowledge flows (see Pavitt, 1984). On the basis of the above-mentioned criteria, Pavitt identified four large sectorial groupings: (PAVITT 1) Supplier dominated-“dominated by suppliers"-which includes textiles (textiles); footwear (footwear); food and beverage sectors (food and beverages); paper and printing (paper and printing); timber (wood). (PAVITT 2) Intensive scale- "scale-intensive"-which includes base metals (basic metals); motor vehicles and related engines (motor-vehicles, trailers and semitrailers). (PAVITT 3) Specialised suppliers—“specialised suppliers"—which include agricultural and industrial machinery (machinery and equipment); office machines (office, accounting and computing machinery); optical, precision and medical instruments (medical, precision and optical instruments). (PAVITT4) Science based-“science based"-which includes chemistry (chemicals); pharmaceutical (pharmaceuticals); electronics (electronics). Each grouping is considered characterised by internal regularities regarding the potential sources of innovation; the type of innovations; their degree of appropriability; the height of barriers to entry and the average size of the companies.
} 


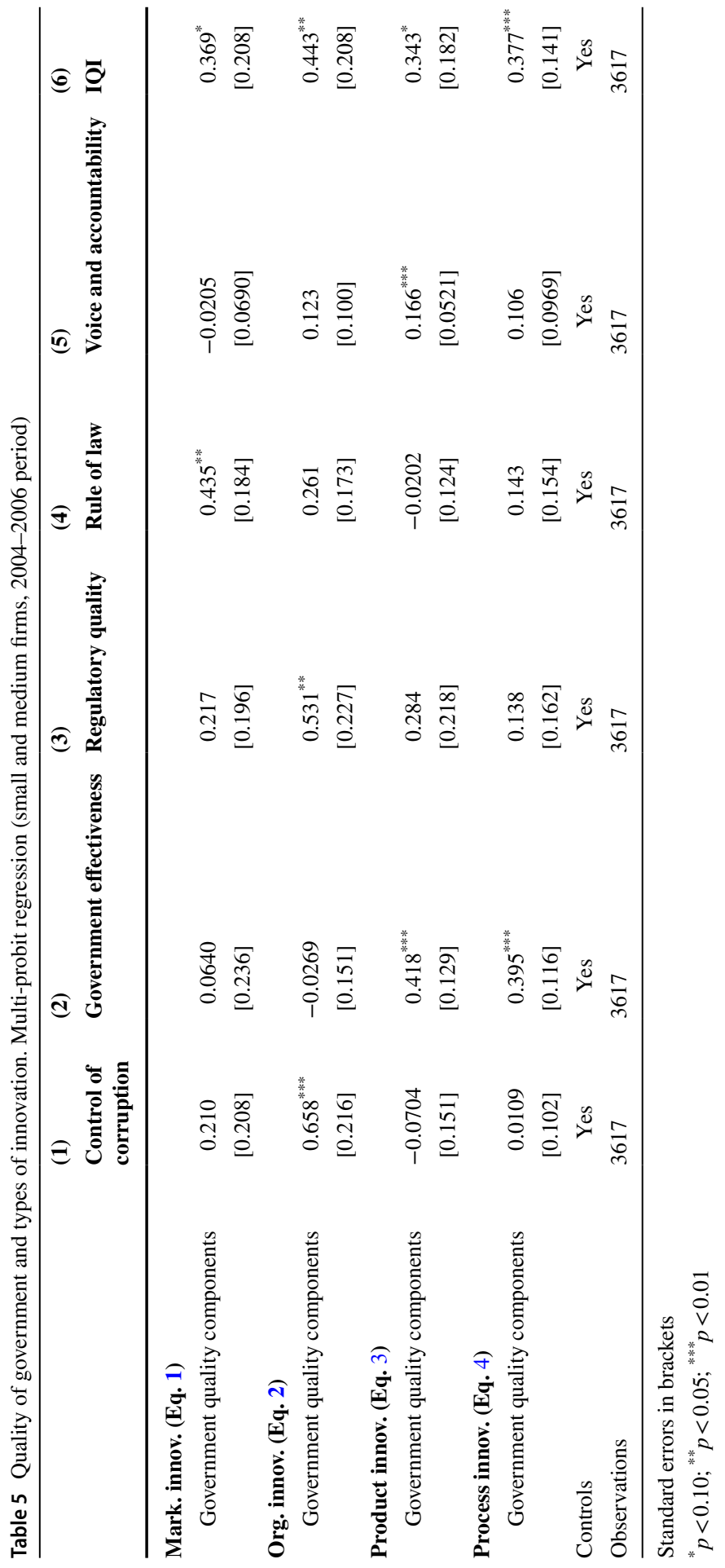


Table 6 Quality of government and types of innovation. Multi-probit regression (PAVITT classification, 2004-2006 period)

(1) (2) (3)

Supplier- Specialised suppliers $\quad$ Scale-intensive + sciencedominated

\begin{tabular}{|c|c|c|c|}
\hline \multicolumn{4}{|l|}{ Mark. innov. (Eq. 1) } \\
\hline \multirow[t]{2}{*}{ Control of corruption } & 0.355 & 0.169 & 0.215 \\
\hline & {$[0.317]$} & {$[0.275]$} & {$[0.220]$} \\
\hline \multirow[t]{2}{*}{ Government effectiveness } & 0.295 & -0.121 & -0.480 \\
\hline & [0.244] & {$[0.504]$} & {$[0.311]$} \\
\hline \multirow[t]{2}{*}{ Regulatory quality } & 0.206 & -0.136 & $0.625^{* *}$ \\
\hline & {$[0.231]$} & {$[0.259]$} & {$[0.256]$} \\
\hline \multirow[t]{2}{*}{ Rule of law } & $0.443^{*}$ & $0.710^{* *}$ & -0.00171 \\
\hline & {$[0.236]$} & {$[0.276]$} & {$[0.418]$} \\
\hline \multirow[t]{2}{*}{ Voice and accountability } & 0.0211 & $-0.286^{* *}$ & 0.181 \\
\hline & {$[0.136]$} & {$[0.133]$} & [0.122] \\
\hline \multirow[t]{2}{*}{ IQI } & $0.501^{*}$ & 0.213 & 0.106 \\
\hline & [0.303] & {$[0.399]$} & {$[0.288]$} \\
\hline \multicolumn{4}{|l|}{ Org. innov. (Eq. 2) } \\
\hline \multirow[t]{2}{*}{ Control of corruption } & $0.327^{*}$ & 0.501 & 0.425 \\
\hline & [0.184] & {$[0.507]$} & {$[0.280]$} \\
\hline \multirow[t]{2}{*}{ Government effectiveness } & 0.325 & 0.311 & -0.191 \\
\hline & {$[0.230]$} & [0.407] & {$[0.376]$} \\
\hline \multirow[t]{2}{*}{ Regulatory quality } & $0.528^{* * *}$ & $0.556^{*}$ & 0.463 \\
\hline & {$[0.134]$} & {$[0.313]$} & [0.302] \\
\hline \multirow[t]{2}{*}{ Rule of law } & 0.210 & -0.0144 & 0.164 \\
\hline & {$[0.225]$} & {$[0.173]$} & {$[0.255]$} \\
\hline \multirow[t]{2}{*}{ Voice and accountability } & $0.299^{* * * *}$ & $0.258^{* *}$ & 0.0171 \\
\hline & {$[0.110]$} & [0.103] & {$[0.155]$} \\
\hline \multirow[t]{2}{*}{ IQI } & $0.579^{* * *}$ & 0.705 & 0.185 \\
\hline & {$[0.152]$} & {$[0.450]$} & {$[0.211]$} \\
\hline \multicolumn{4}{|l|}{ Product innov. (Eq. 3) } \\
\hline \multirow[t]{2}{*}{ Control of corruption } & -0.146 & $0.271^{* *}$ & 0.0269 \\
\hline & {$[0.144]$} & {$[0.136]$} & {$[0.280]$} \\
\hline \multirow[t]{2}{*}{ Government effectiveness } & $0.526^{* * *}$ & 0.534 & 0.171 \\
\hline & {$[0.196]$} & {$[0.371]$} & {$[0.363]$} \\
\hline \multirow[t]{2}{*}{ Regulatory quality } & $0.290^{*}$ & $0.443^{* * *}$ & $0.617^{*}$ \\
\hline & [0.173] & {$[0.144]$} & {$[0.346]$} \\
\hline \multirow[t]{2}{*}{ Rule of law } & 0.122 & 0.286 & -0.448 \\
\hline & [0.167] & {$[0.232]$} & {$[0.289]$} \\
\hline \multirow[t]{2}{*}{ Voice and accountability } & 0.0527 & -0.0376 & $0.453^{* * *}$ \\
\hline & {$[0.106]$} & {$[0.111]$} & [0.101] \\
\hline \multirow[t]{2}{*}{ IQI } & $0.373^{*}$ & $0.610^{* *}$ & 0.304 \\
\hline & {$[0.225]$} & {$[0.296]$} & {$[0.332]$} \\
\hline
\end{tabular}


Table 6 (continued)

(1)

(2)

(3)

$\begin{array}{lll}\begin{array}{l}\text { Supplier- } \\ \text { dominated }\end{array} & \text { Specialised suppliers } & \begin{array}{l}\text { Scale-intensive + science- } \\ \text { based }\end{array}\end{array}$

Process innov. (Eq. 4)

\begin{tabular}{lccc} 
Control of corruption & 0.0393 & $0.561^{* * *}$ & 0.110 \\
& {$[0.165]$} & {$[0.209]$} & {$[0.277]$} \\
Government effectiveness & $0.559^{* * *}$ & 0.259 & 0.280 \\
& {$[0.132]$} & {$[0.338]$} & {$[0.270]$} \\
Regulatory quality & 0.0880 & 0.171 & $0.626^{* *}$ \\
\multirow{2}{*}{ Rule of law } & {$[0.180]$} & {$[0.243]$} & {$[0.264]$} \\
& 0.249 & 0.0177 & -0.0461 \\
Voice and accountability & {$[0.171]$} & {$[0.239]$} & {$[0.388]$} \\
& 0.135 & $-0.168^{*}$ & $0.286^{* *}$ \\
IQI & {$[0.138]$} & {$[0.0964]$} & {$[0.120]$} \\
& $0.496^{* * *}$ & 0.0861 & 0.468 \\
Controls & {$[0.174]$} & {$[0.424]$} & {$[0.349]$} \\
Observations & Yes & Yes & Yes \\
Tes & 2515 & 1360 & 1186
\end{tabular}

Standard errors in brackets

${ }^{*} p<0.10 ;{ }^{* *} p<0.05 ;{ }^{* * *} p<0.01$

significantly vary across industrial sectors. Moreover, as emphasised by Malerba (2002), the effects of national institutions on sectoral innovation depend on the sector examined. Specifically, due to the existence of sectoral-specific factors, firms operating in different sectors react unevenly to the incentives provided by a changing institutional environment.

Evidence reported in Table 6 suggests that the rule of law and the composite indicator display a positive, albeit weak, effect on the likelihood of introducing marketing innovation once the sub-sample of supplier-dominated firms is considered, while the rule of law is the only dimension of government quality that affects the probability of marketing innovation in the case of specialised suppliers. For scaleintensive suppliers, we instead find evidence of a positive relationship between regulatory quality and the variable of interest. Organisational innovation, in the case of supplier-dominated firms, is significantly affected by improved regulatory quality, voice and accountability and the composite indicator, while increased control of corruption exerts a weak positive effect on the likelihood of organisational innovation for this sub-set of firms. In the case of specialised suppliers, we show that organisational innovation is enhanced by higher voice and accountability, while regulatory quality exhibits a weak positive effect, as it is significant at $10 \%$ level only. The quality of government is instead shown to have so significant impact on the organisational decisions of scale-intensive suppliers. Product innovation is instead found to be enhanced, in the case of supplier-dominated firms, by increased government 
effectiveness, regulatory quality and the composite indicator, though these two indices are significant at $10 \%$ level only. Increased control of corruption, regulatory quality and the composite measure of government quality drive the probability of product innovation in the case of specialised suppliers. A significant positive effect of voice and accountability and a weak effect of regulatory quality are instead found on the likelihood of product innovation for scale-intensive suppliers.

Finally, our econometric evidence reveals that the probability of introducing process innovation in supplier-dominated firms positively depends on government effectiveness and the composite indicator of government quality, while we respectively document a significant effect for control of corruption in the case of specialised suppliers and for government effectiveness and regulatory quality once scaleintensive suppliers are analysed. All in all, our results indicate that the effects of government quality are larger for supplier-dominated firms and, in line with the predictions of Malerba (2002), the evidence reported here indicates that the impact and the relevance of government quality upon firms' innovative performance significantly depends upon the economic sector analysed.

\section{How Does Territorial Diversification Affect the Estimates?}

As Italian regional economies are characterised by a marked dualism, to further assess the effects of government quality of innovation and in order to have a better understanding of how the quality of governance affects innovation at the local level, we provide a set of econometric estimates in which firms are partitioned according to their geographical location. In particular, Italian regions (i.e. NUTS2) are partitioned in three different macro-areas, respectively represented by North, Centre and South-Islands. This type of analysis is also motivated by a set of contributions, see for instance Cannari (2009), Tabellini (2010), Mauro and Pigliaru (2011) and D' Agostino and Scarlato (2015), which have shown that a significant portion of the Italian regional divides can be ascribed to differences in the effectiveness of the institutional environment. It turns out that, a priori, it is reasonable to assume that the effects of government quality on firms' innovation vary across the main macro-areas and we expect macro-regions with a better quality of government to exhibit a higher propensity to innovate. Our discussion begins by examining the results of Table 7 , in which we examine the nexus between government quality and innovation for firms operating in the Northern regions.

The quality of government, in the case of marketing innovation, is shown to have a limited impact upon the dependent variable, as only rule of law and the composite index are found to be positive and statistically significant. A similar picture emerges with respect to organisational innovation, as only voice and accountability is found to significantly affect the variable of interest. Once the focus is on product innovation, government effectiveness, regulatory quality, voice and accountability and the IQI index are found to positively and significantly affect the likelihood of introducing new products in the market. We conclude our analysis concerning firms operating in Northern regions by assessing 


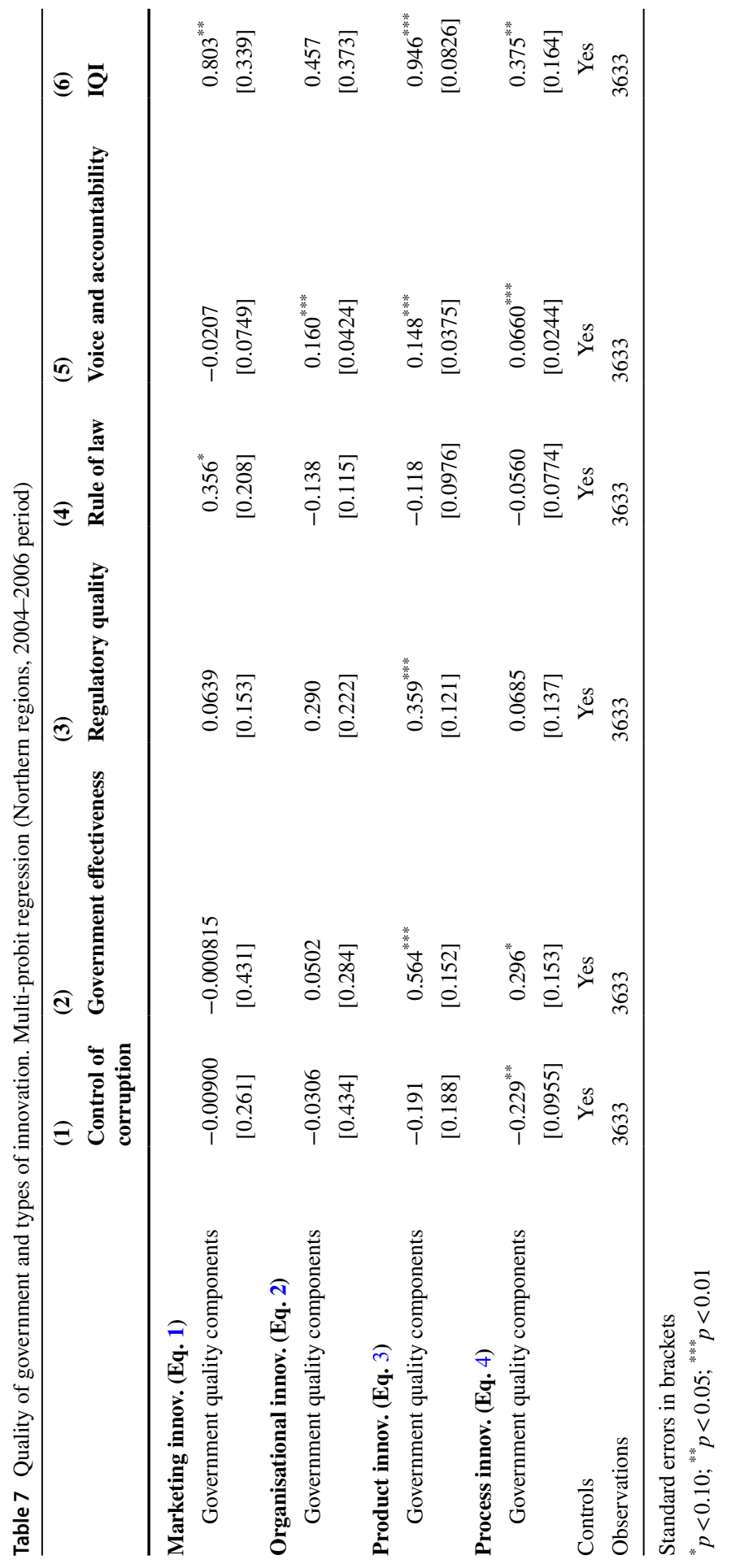


the impact of government quality on process innovation. Among the set of government quality indicators included in our econometric analysis, we show that government effectiveness and voice and accountability are the two dimensions which are found to positively and significantly affect the variable of interest. Moreover, the left-hand-side variable is found to positively react to variations in the government quality as a whole, as shown by the positive and significant coefficient of the composite indicator.

In Table 8 , we examine the relevance of government quality on the innovation decisions of firms operating in Centre regions. The evidence reported in Table 8 indicates that the quality of government has no role in explaining the innovation decisions of firms located in this macro-area, though we document a positive, albeit weakly significant, effect of government effectiveness on process innovation.

We conclude this robustness check by assessing the role of government quality in explaining the innovative performance of firms operating in Southern regions. Results reported in Table 9 indicate that the quality of government has a limited role in explaining marketing innovation, though we find evidence of a weak positive effect for the rule of law. Moreover, while the quality of government exerts no significant effect on product and process innovation for firms located in this macroarea, the opposite holds with respect to organisational innovation, as the latter is positively correlated with control of corruption, regulatory quality, rule of law, voice and accountability and the IQI index, while no statistically significant impact is found for government effectiveness.

The evidence reported in this section can be interpreted in two different ways. More specifically, while on the one hand it can be argued, following the afore-mentioned contributions of Cannari (2009), Tabellini (2010), Mauro and Pigliaru (2011) and D' Agostino and Scarlato (2015), that effective and efficient local governments, as in the case of Northern regions, are growth-enhancing, on the other, the presence of a weak institutional environment, as in the case of Southern regions, hampers innovation and retards economic growth. At the same time, the significant effect of government quality on product and process innovation found for Northern regions but not for other macro-areas may reflect the innovative characteristics of these different macro-regions and may reflect the relative importance of these dimensions of innovation in the different macro-areas of the country.

\section{Limits of the Analysis}

Though the evidence reported in this paper indicates that the quality of government has some role in explaining firms' innovation decisions in Italy, our analysis is not immune from limitations. More specifically, two potential limits are worth mentioning, which are respectively represented by the survey nature of the data employed and by the data time period.

Relatively to the survey nature of the data employed in the current analysis, a major concern is represented by the fact that firms might underestimate or overestimate their innovative activities. As some contributions have pointed out, this is 


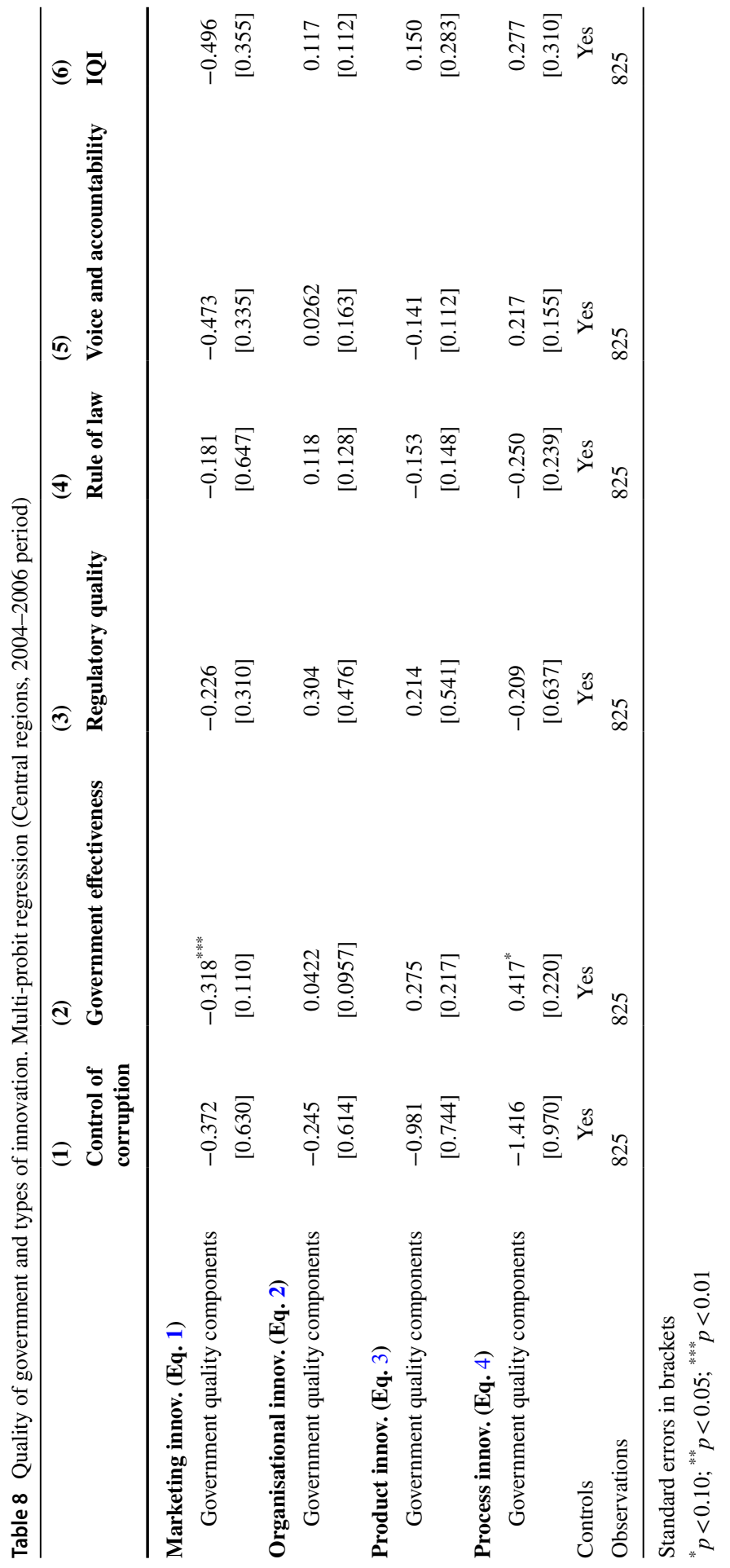




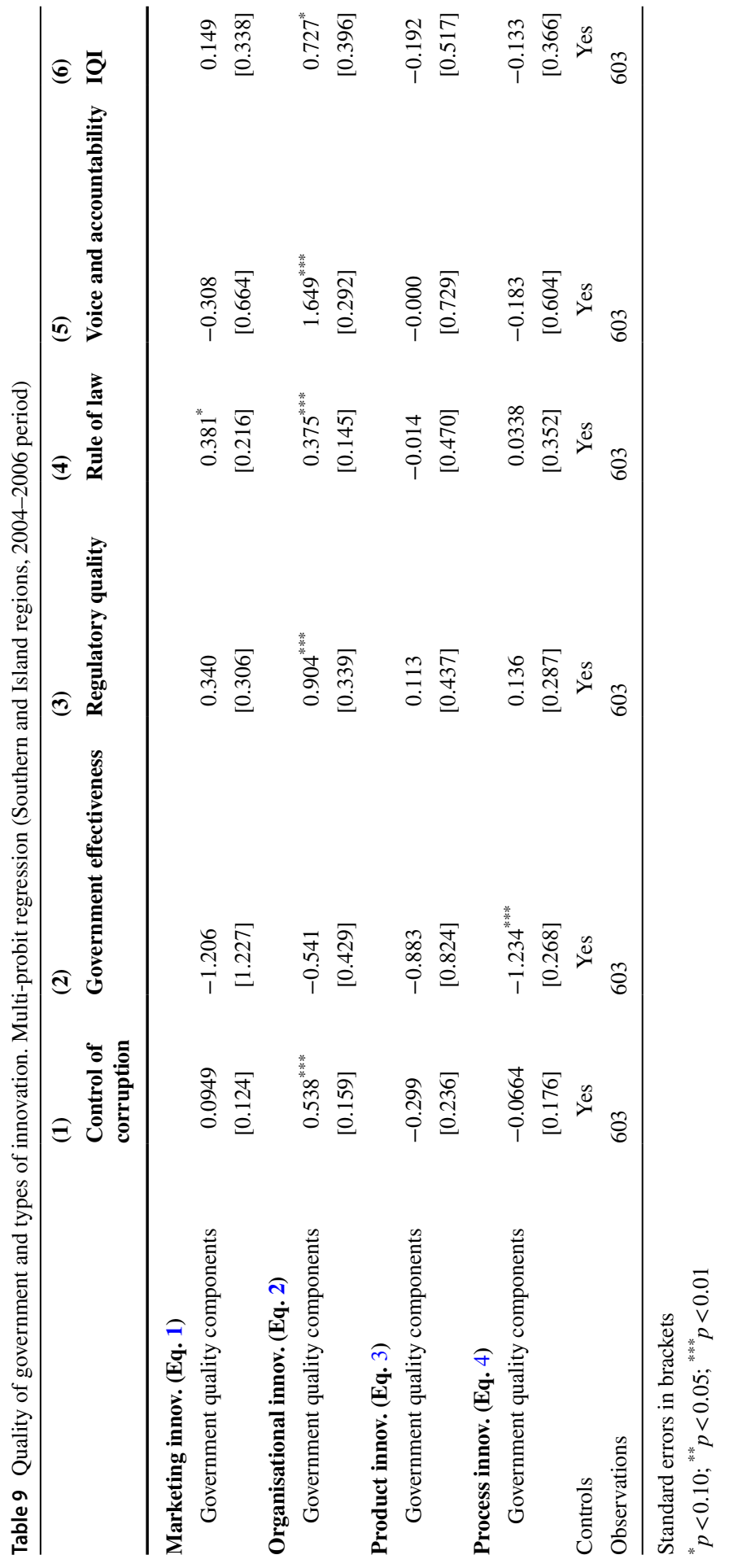


very unlikely to occur for three main reasons. Indeed, as emphasised by Herrera and Minetti (2007) and Minetti and Zhu (2011), the Italian law (675/1996) protects the use of personal data and forbids the use of personal information for purposes other than statistical recording. The second is instead related to the fact the CapitaliaMediocredito is specialised in the financing of firms and relies on a specialised personnel. Moreover, the answers reported by the firms are subject to several filters and double-checked by the personnel of Capitalia-Mediocredito. Finally, even if there could be measurement errors, a bias in the estimated parameters could occur if and only if the left-hand-side variables exhibit some systematic correlation with one or more regressors. Though the survey nature of the data employed does not represent a major issue, a relevant concern is instead related to the data time period. Indeed, our results might significantly differ if an alternative- and more recent-sample period would be considered. This seems to be particularly true if we also consider the fact that, following the financial crisis, Italian firms experienced a contraction in their levels of investments and the fact that some economic sectors have been particularly hit by the various recessionary episodes (ISTAT, 2012). This also casts doubt about the validity of the proposed policy prescriptions, with the implication that any policy implication reported in this paper must be taken with caution, due to the fact that the analysis is based on data from the 2004-2006 period.

\section{Conclusions and Discussions}

The relevance of the technological progress and of the quality of institutions has been widely recognised in the economic literature. More specifically, while on the one hand the endogenous growth theory has emphasised the relevance of technological progress as the main engine of economic growth (Aghion \& Howitt, 1992, 2007; Aghion et al., 2016; Lucas, 1988; Romer, 1990), on the other the contributions devoted to the identification of the determinants of long-run growth (Hall \& Jones, 1999; Acemoglu et al., 2001; Dollar \& Kraay, 2003; Acemoglu et al., 2005, Acemoglu \& Robinson, 2010) ascribed the observed diverging cross-country patterns in the levels of per-capita income to differences in the relative quality of institutions and in their effectiveness in defining and protecting property rights.

Not surprisingly, as institutions, innovation and long-run growth are strictly interconnected, a considerable amount of research has been devoted to assess how the quality of institutions affects the innovative performances of countries and firms.

Measures of institutions commonly employed in the empirical literature include corruption (Aghion et al., 2016; Anokhin \& Schulze, 2009; Ayyagari et al., 2014; Dincer, 2019; Ellis et al., 2019; Ervits \& Zmuda, 2018; Lee et al., 2020; Paunov, 2016) and political stability (Alesina \& Perotti, 1996; Waguespack et al., 2005; Hoti \& McAleer, 2006; Allard et al., 2012; Gholipur, 2019), though more recent contributions, see for instance Giménez and Sanaú (2007), Soumaré and Tchana Tchana (2015), Asongu et al. (2018), Cahn et al. (2019) and Clò et al. (2020), have instead widened the set of governance measures included in empirical specifications by relying on the full set of governance quality indices proposed by the World Bank. 
Though the general consensus among these papers is that the quality of government plays a key role in shaping the innovative performances of countries and firms, the major limitation arising from the afore-mentioned literature is represented by the fact that most of these studies rely on a single measure of innovation, such as the amount of patents issued, but do not provide any evidence on how the quality of the government interacts with different dimensions of innovation.

In this paper, by combining firm-level information collected by Capitalia and the Institutional Quality Index (IQI) dataset developed by Nifo and Vecchione (2014) at provincial level (NUTS3), we propose the application of a multi-probit model to assess the effects of alternative measures of government quality, such as control of corruption, government effectiveness, rule of law, regulatory quality and voice and accountability, on four alternative dimensions of innovation, namely, marketing innovation, organisational innovation, product innovation and process innovation, whose relevance for firms' performance has been widely recognised in the literature. More specifically, product and process innovation respectively allow firms to increase the price of the goods produced and to cut average production costs (Cohen and Klepper, 1996), organisational innovation facilitates the development of new products and processes (Camisón \& Villar-López, 2014) and increases productivity (Caroli \& Van Reenen, 2001), while marketing innovation allows firms to increase the sales income Karlsson and Tavassoli (2016).

The findings presented in this paper suggest that the impact of governance on innovation varies depending on the dimension of innovation considered. Specifically, we show that while marketing innovation is positively affected by increased rule of law, higher control of corruption, regulatory quality and voice and accountability increase the likelihood of introducing new and more efficient organisational processes. The propensity to introduce new products in the market and new processes are both positively affected by government effectiveness, regulatory quality and voice and accountability.

Though our general findings indicate that the higher is the quality of government, the higher is the propensity to undertake innovative activities, to assess the robustness of benchmark results, we propose a set of econometric estimates where firms are partitioned according to their size, PAVITT classification and geographical location, a choice which is grounded on the previous economic literature. More specifically, as various contributions in the literature have pointed out (Agostino et al., 2020; LiPuma et al., 2013; Paunov, 2016), the effects of government quality upon export performance, innovation and productivity have been found to decrease with size, with the implication the small and medium firms are generally more sensitive to variations in the quality of government. On the other hand, the partition of firms according to the PAVITT classification is justified by the fact that, as emphasised by Malerba (2002), the impact of governmental institutions on innovation crucially depends on the sector examined, with the presence of sectoral-specific factors which unevenly affects the incentives of firms operating in different industrial sectors. Moreover, as Italy is characterised by large regional divides, both in terms of innovation intensity and quality of government, we propose a set of econometric estimates where firms are partitioned according to their geographical location and assess how the quality of government influences 
innovation in the three main macro-areas of the country, namely, North, Centre and South and Island. The relevance of this econometric exercise lies in the fact that, as shown by the literature devoted to the analysis of regional divides in Italy (see for instance Cannari, 2009; Tabellini, 2010; Mauro \& Pigliaru, 2011; D' Agostino \& Scarlato, 2015), one of the main causes of regional divides among peripheral Southern regions and the core regions in the Centre and in the North is represented by the different effectiveness and efficiency of the institutional environment.

The evidence obtained with the first robustness check reveals that the quality of government has a larger impact of small and medium firms, while limited role is found on the innovation of large firms. More specifically, while the quality of government is ineffective in explaining the probability of introducing marketing and product innovation for large firms, increased voice and accountability has a positive effect on organisational processes, while tighter anti-corruption regulations and voice and accountability stimulate the introduction of new products in the market. While a limited role of government quality is found for large firms, the opposite holds true for small firms, for which the quality of government seems to be largely more relevant. In particular, rule of law is found to affect marketing innovation, while organisational processes are influenced by both control of corruption and regulatory quality. Product and process innovation, on the other hand, positively depend upon government effectiveness and, in the case of the former, by voice and accountability as well.

Once firms are portioned according to the PAVITT classification, our results indicate that the effects of government quality significantly vary depending on the industrial sector, with a preeminent role for government effectiveness and regulatory quality, which are found to stimulate innovative activities that involve both products and processes.

Finally, once the analysis is conducted at geographical level, the findings reported in this paper indicate that the quality of government has a larger impact on the innovation of firms located in the North, especially on product and process innovation. On the other hand, while for firms operating in the Centre the quality of government plays no role in explaining innovation, we find evidence of a significant effect of the quality of government on organisational innovation for firms in the South and Islands.

The results of this econometric exercise can be therefore interpreted in two different ways. While on the one hand it can argued that the propensity to innovate is higher where institutions are effective and efficient, as in the case of the Northern regions, in the case of the South the presence of a weak and ineffective institutional environment hampers innovation, hence retarding economic growth. At the same time, the evidence obtained through this econometric analysis might reflect the propensity towards innovation of the different macro-areas and a higher intensity, especially in terms of product and process innovation, in Northern regions.

Empirical findings presented in this paper have therefore several policy implications, though the latter must be taken with cautions, as the data employed refer to the 2004-2006 period. Though in line with Méon and Weill (2005, page 87) we share the opinion that "Improving governance can arguably be deemed too evasive 
an objective to be really achievable", our estimates suggest that considerable efforts should be devoted to improve the quality of specific dimensions of government quality, most notably regulatory quality, government effectiveness and voice and accountability, given their positive and significant impact on two major dimensions of innovation, such as product and proves innovation.

Furthermore, the battery of robustness checks performed in the paper is relevant not only from a quantitative perspective but in terms of policy implications as well. In particular, given the structure of the Italian economy, which is characterised by the prevalence of small and medium firms, the implementation of tailored policies for these firms aimed at reducing the bureaucratic costs related to investments and increasing the efficiency of public services seem to be necessary to improve their innovative performance, therefore increasing productivity and output levels.

Finally, the existence of large and persistent regional divides between the core regions of Centre and North and the peripheral ones of the South calls for the implementation of policies aimed at reducing the technological gap between these macroareas and to allow Southern regions to catch-up the reminder of country. From this perspective, in line with the view of Capello (2016), as Southern regions lack of the appropriate environment to perform innovation, national policies aimed at favouring imitation for Southern regions are, in our opinion, highly recommendable.

\section{Declarations}

Conflict of Interest The authors declare no competing interests.

Open Access This article is licensed under a Creative Commons Attribution 4.0 International License, which permits use, sharing, adaptation, distribution and reproduction in any medium or format, as long as you give appropriate credit to the original author(s) and the source, provide a link to the Creative Commons licence, and indicate if changes were made. The images or other third party material in this article are included in the article's Creative Commons licence, unless indicated otherwise in a credit line to the material. If material is not included in the article's Creative Commons licence and your intended use is not permitted by statutory regulation or exceeds the permitted use, you will need to obtain permission directly from the copyright holder. To view a copy of this licence, visit http://creativecommons.org/licen ses/by/4.0/.

\section{References}

Acemoglu, D., Johnson, S., \& Robinson, J. A. (2001). The colonial origins of comparative development: An empirical investigation. American Economic Review, 91(5), 1369-1401. https://doi.org/10.1257/ aer.91.5.1369

Acemoglu, D., Johnson, S., \& Robinson, J. A. (2005). Institutions as fundamental cause of long run growth (pp. 385-472). Handbook of economic growth.

Acemoglu, D., \& Robinson, J. A. (2010). The role of institutions in growth and development. Review of Economics and Institutions, 1(2), 1-33. https://doi.org/10.5202/rei.v1i2.14

Aghion, P., \& Howitt, P. (1992). A model of growth through creative destruction. Econometrica, 60(2), 323-351. https://doi.org/10.2307/2951599

Aghion, P., \& Howitt, P. (2007). Capital, innovation, and growth accounting. Oxford Review of Economic Policy, 23(1), 79-93. https://doi.org/10.1093/oxrep/grm007 
Aghion, P., Akcigit, U., Cagé, J., \& Kerr, W. R. (2016). Taxation, corruption, and growth. European Economic Review, 86, 24-51. https://doi.org/10.1016/j.euroecorev.2016.01.012

Agostino, M., Di Tommaso, M. R., Nifo, A., Rubini, L., \& Trivieri, F. (2020). Institutional quality and firms' productivity in European regions. Regional Studies, 54(9), 1-15. https://doi.org/10.1080/ 00343404.2020 .1712689

Alam, A., Uddin, M., \& Yazdifar, H. (2019). Institutional determinants of R\&D investment: Evidence from emerging markets. Technological Forecasting \& Social Change, 138, 34-44. https://doi.org/ 10.1016/j.techfore.2018.08.007

Aldieri, L., Barra, C., Vinci, C. P., \& Zotti, R. (2021). The joint impact of different types of innovation on firm's productivity: Evidence from Italy. Economics of Innovation and New Technology, 30(2), 151-182. https://doi.org/10.1080/10438599.2019.1685211

Alesina, A., \& Perotti, R. (1996). Income distribution, political stability and investments. European Economic Review, 40(6), 1203-1228. https://doi.org/10.1016/0014-2921(95)00030-5

Allard, G., Martinez, C. A., \& Williams, C. (2012). Political instability, pro-business market reforms and their impact on national systems of innovation. Research Policy, 41(3), 638-651. https://doi.org/10. 1016/j.respol.2011.12.005

Anderlini, L., Felli, L., Immordino, G., \& Biboni, A. (2013). Legal institutions, innovation, and growth. International Economic Review, 54(3), 937-956. https://doi.org/10.1111/iere.12023

Anokhin, S., \& Schulze, W. S. (2009). Entrepreneurship, innovation, and corruption. Journal of Business Venturing, 24(5), 465-476. https://doi.org/10.1016/j.jbusvent.2008.06.001

Asongu, S. A., Nwachukwu, J. C., \& Orim, S. M. I. (2018). Mobile phones, institutional quality and entrepreneurship in Sub-Saharan Africa. Technological Forecasting \& Social Change, 131, 183203. https://doi.org/10.1016/j.techfore.2017.08.007

Ayyagari, M., Demirgüç-Kunt, A., \& Maksimovic, V. (2014). Bribe payments and innovation in developing countries: Are innovative firms disproportionately affected? Journal of Financial and Quantitative Analysis, 49(1), 51-75. https://doi.org/10.1017/S002210901400026X

Barasa, L., Knoben, J., Vermeulen, P., Kimuyu, P., \& Kinyanjui, B. (2017). Institutions, resources and innovation in East Africa: A firm level approach. Research Policy, 46(1), 280-291. https://doi.org/ 10.1016/j.respol.2016.11.008

Barra, C., Maietta, O. W., \& Zotti, R. (2019). Academic excellence, local knowledge spillovers and innovation in Europe. Regional Studies, 53(7), 1058-1069. https://doi.org/10.1080/00343404.2018.1540865

Boettke, P., \& Fink, A. (2011). Institutions first. Journal of Institutional Economics, 7(4), 499-504. https://doi.org/10.1017/S1744137411000063

Cahn, N. P., Schinckus, C., \& Thanh, S. D. (2019). Do economic openness and institutional quality influence patents? Evidence from GMM systems estimates. International Economics, 157, 134-169. https://doi.org/10.1016/j.inteco.2018.10.002

Camisón, C., \& Villar-López, A. (2014). Organizational innovation as an enabler of technological innovation capabilities and firm performance. Journal of Business Research, 67(1), 2891-2902. https:// doi.org/10.1016/j.jbusres.2012.06.004

Cannari, L. (2009). Mezzogiorni e Politiche Regionali. Banca d' Italia.

Cappellari, L., \& Jenkins, S. (2003). Multivariate probit regression using simulated maximum likelihood. Stata Journal, 3, 221-222.

Capello, R. (2016). What makes Southern Italy still lagging behind? A diachronic perspective of theories and approaches. European Planning Studies, 24(4), 668-686. https://doi.org/10.1080/09654313. 2015.1128402

Caroli, E., \& Van Reenen, J. (2001). Skill-biased organizational change? Evidence from a panel of British and French establishments. Quarterly Journal of Economics, 116(4), 1449-1492. https://doi.org/10. 1162/003355301753265624

Castellucci, F. (2015). Institutional voids or organizational resilience? Business groups, innovation, and market development in Latin America. World Development, 70, 43-58. https://doi.org/10.1016/j. worlddev.2014.12.014

Clò, S., Florio, M., \& Rentocchini, F. (2020). Firm ownership, quality of government and innovation: Evidence from patenting in the telecommunication industry. Research Policy, 49(5), 1-16. https://doi.org/ 10.1016/j.respol.2020.103960

Cohen, W. M., \& Klepper, S. (1996). Firm size and the nature of innovation within industries: the case of process and product R\&D. The Review of Economics and Statistics, 232-243. 
D' Agostino, G., \& Scarlato, M. (2015). Innovation, socio-institutional conditions and economic growth in the Italian regions. Regional Studies, 45(9), 1514-1534. https://doi.org/10.1080/00343404.2013. 838000

De Waldemar, F. S. (2012). New products and corruption: Evidence from Indian firms. Developing Economies, 50(3), 268-284. https://doi.org/10.1111/j.1746-1049.2012.00171.x

Dewett, T. (2007). Linking intrinsic motivation, risk taking, and employee creativity in an R\&D environment. R\&D Management, 37(3), 197-208. https://doi.org/10.1111/j.1467-9310.2007.00469.x

Dincer, O. (2019). Does corruption slow-down innovation? Evidence from a cointegrated panel U.S. states. European Journal of Political Economy, 56, 1-10. https://doi.org/10.1016/j.ejpoleco.2018. 06.001

Dollar, D., \& Kraay, A. (2003). Institutions, trade and growth. Journal of Monetary Economics, 50(1), 133-162. https://doi.org/10.1016/S0304-3932(02)00206-4

Ellis, J., Smith, J., \& White, R. (2019). Corruption and corporate innovation. Journal of Financial and Quantitative Analysis, 55(7), 1-51. https://doi.org/10.1017/S0022109019000735

Ervits, I., \& Zmuda, M. (2018). A cross-country comparison of the effects of institutions on internationally oriented innovation. Journal of International Entrepreneurship, 16, 486-503. https://doi.org/10. 1007/s10843-018-0225-8

Esposti, R., \& Pierani, P. (2003). Building the knowledge stock: Lags, depreciation, and uncertainty in R\&D investment and link with productivity growth. Journal of Productivity Analysis, 19, 33-58. https://doi.org/10.1023/A:1021818019626

Faust, J. (2008). Are more democratic donor countries more development oriented? Domestic institutions and external development promotion in OECD countries. World Development, 36(3), 383-398. https://doi.org/10.1016/j.worlddev.2007.03.006

Furtan, W. H., \& Sauer, J. (2008). Determinants of food industry performance: Survey data and regressions for Denmark. Journal of Agricultural Economics, 59(3), 555-573.

Geweke, J. (1989). Bayesian inference in econometric models using Monte Carlo integration. Econometrica, 57(6), 1317-1339. https://doi.org/10.2307/1913710

Gholipur, H. F. (2019). The effects economic policy and political uncertainties on economic activities. Research in International Business and Finance, 48, 210-218. https://doi.org/10.1016/j.ribaf.2019. 01.004

Giménez, G., \& Sanaú, J. (2007). Interrelationship among institutional infrastructure, technological innovation and growth. An empirical evidence. Applied Economics, 39(10), 1267-1282. https://doi.org/ $10.1080 / 00036840500438988$

Golden M.A., \& Picci, L. (2005). Proposal for a new measure of corruption, and tests using Italian data. Economics \& Politics, 17(03), 37-75.

Hajivassiliour, V. A., \& McFadden, D. L. (1998). The method of simulated scores for the estimation of LDV models. Econometrica, 66(4), 863-896. https://doi.org/10.2307/2999576

Hall, B. H., Lotti, F., \& Mairesse, J. (2013). Evidence on the impact of R\&D and ICT investments on innovation and productivity in Italian firms. Economics of Innovation and New Technology, 22(3), 300328

Hall, R. E., \& Jones, C. I. (1999). Why do some countries produce so much more output per worker than others? Quarterly Journal of Economics, 114, 83-116. https://doi.org/10.1162/003355399555954

Herrera, A. M., \& Minetti, R. (2007). Informed finance and technological change: Evidence from credit relationships. Journal of Financial Economics, 83, 223-269. https://doi.org/10.1016/j.jfineco.2005. 12.001

Hoti, S., \& McAleer, M. (2006). How does country risk affect innovation? An application to foreign patents registered in the USA. Journal of Economic Surveys, 20(4), 691-714. https://doi.org/10.1111/j. 1467-6419.2006.00263.x

Immordino, G., Pagano, M., \& Polo, M. (2011). Incentives to innovate and social harm: Laissez-faire, authorization or penalties? Journal of Public Economics, 95(7-8), 864-876. https://doi.org/10. 1016/j.jpubeco.2011.01.011

ISTAT. (2012). Rapporto Annuale 2012. Extracted on 09/07/2021.

Jiao, H., Coo, C. K., \& Cui, Y. (2015). Legal environment, government effectiveness and firms' innovation in China: Examining the moderating influence of government ownership. Technological Forecasting \& Social Change, 96, 15-24. https://doi.org/10.1016/j.techfore.2015.01.008

Karlsson, C., \& Tavassoli, S. (2016). Innovation strategies of firms: What strategies and why? Journal of Technology Transfer, 41, 1483-1506. https://doi.org/10.1007/s10961-015-9453-4 
Kaufmann, D., Kraay, A., \& Mastruzzi, M. (2010). The worldwide governance indicators: Methodology and analytical issues. Policy research working paper series, No. 5430, The World Bank.

Keane, M. P. (1994). A computationally practical simulation estimator for panel data. Econometrica, 62(1), 95-116. https://doi.org/10.2307/2951477

Kwan, L. Y. Y., \& Chiu, C. (2015). Country variations in different innovation outputs: The interactive effect of institutional support and human capital. Journal of Organizational Behavior, 36(7), 10501070. https://doi.org/10.1002/job.2017

Lee, C. C., Wang, C. W., \& Ho, S. J. (2020). Country governance, corruption and the likelihood of firms' innovation. Economic Modelling, 92, 1-13. https://doi.org/10.1016/j.econmod.2020.01.013

LiPuma, J., Newbert, S. L., \& Doh, J. P. (2013). The effect of institutional quality on firm export performance in emerging economies: A contingency model of firm age and size. Small Business Economics, 40, 817-841. https://doi.org/10.1007/s11187-011-9395-7

Lucas, R. E., Jr. (1988). On the mechanics of economic development. Journal of Monetary Economics, 22, 3-14. https://doi.org/10.1016/0304-3932(88)90168-7

Maddala, G. S. (1983). Limited-dependent and qualitative variables in econometrics. Cambridge University Press.

Maietta, O. W. (2015). Determinants of university-firm R\&D collaboration and its impact on innovation: A perspective from a low-tech industry. Research Policy, 44(7), 1341-1359. https://doi.org/10. 1016/j.respol.2015.03.006

Maietta, O. W., Barra, C., \& Zotti, R. (2017). Innovation and university-firm R\&D collaboration in the European food and drink industry. Journal of Agricultural Economics, 68(3), 749-780. https://doi. org/10.1111/1477-9552.12208

Malerba, F. (2002). Sectoral systems of innovation and production. Research Policy, 31(2), 247-264. https://doi.org/10.1016/S0048-7333(01)00139-1

Mancini, M. C., \& Consiglieri, C. (2016). Innovation and marketing strategies for PDO products: The case of "Parmigiano Reggiano" as an ingredient. Bio-based and Applied Economics Journal, Italian Association of Agricultural and Applied Economics (AIEAA), 5(2), September.

Mauro, L. \& Pigliaru, F. (2011). Social capital, institutions and growth: Further lessons from the Italian regional divide. CRENoS working paper number 3. Centro Ricerche Economiche Nord Sud (CRENoS), University of Cagliari, Cagliari.

Medda, G., Piga, C., \& Siegel, D. S. (2006). Assessing the returns to collaborative research: Firm-level evidence from Italy. Economics of Innovation and New Technology, 15(1), 37-50. https://doi.org/10. 1080/1043859042000332213

Méon, P. G., \& Weill, L. (2005). Does better governance foster efficiency? An aggregate frontier analysis. Economics of Governance, 6, 75-90. https://doi.org/10.1007/s10101-004-0080-Z

Minetti, R., \& Zhu, S. C. (2011). Credit constraints and firm export: Microeconomic evidence from Italy. Journal of International Economics, 83, 109-125. https://doi.org/10.1016/j.jinteco.2010.12.004

Monfardini, C., \& Radice, R. (2008). Testing exogenity in the bivariate probit model: A Monte Carlo study. Oxford Bulletin of Economics and Statistics, 70, 271-28.

Muscio, A., \& Ciffolilli, A. (2020). What drives the capacity to integrate Industry 4.0 technologies? Evidence from European R\&D projects. Economics of Innovation and New Technology, 29(2), 169183. https://doi.org/10.1080/10438599.2019.1597413

Myrdal, G. (1957). Economic theory and underdeveloped regions. G. Duckworth.

Nifo, A., \& Vecchione, G. (2014). Do institutions play a role in skilled migrations? The case of Italy. Regional Studies, 48(10), 1628-1649. https://doi.org/10.1080/00343404.2013.835799

North, D. C. (1991). Institutions. Journal of Economic Perspectives, 5(1), 97-112. https://doi.org/10. 1257/jep.5.1.97

North, D. C. (1994). Economic performance through time. American Economic Review, 84(3), 359-368.

Oluwatobi, S., Efobi, U., Olurinola, I., \& Alege, P. (2015). Innovation in Africa: Why institutions matter. South African Journal of Economics, 83(3), 390-410. https://doi.org/10.1111/saje.12071

Paunov, C. (2016). Corruption's asymmetric impacts on firm innovation. Journal of Development Economics, 118, 216-231. https://doi.org/10.1016/j.jdeveco.2015.07.006

Pavitt, K. (1984). Patterns of technical change: Towards a taxonomy and a theory. Research Policy, 13, 343-373.

Rodríguez-Pose, A., \& Di Cataldo, M. (2015). Quality of government and innovative performance in the regions of Europe. Journal of Economic Geography, 15(4), 673-706. https://doi.org/10.1093/jeg/ lbu023 
Rodríguez-Pose, A., \& Zhang, M. (2020). The cost of weak institutions for innovation in China. Technological Forecasting \& Social Change, 153, 1-16. https://doi.org/10.1016/j.techfore.2020.119937

Romer, P. M. (1990). Endogenous technological change. Journal of Political Economy, 98(5), 71-102. https://doi.org/10.1086/261725

Saaty, T. L. (1980). The analytic hierarchy process. McGraw-Hill, New York, NY.

Saaty, T. L. (1992). The decision maker for leaders. RWS, Pittsburgh, PA.

Sobel, R. S. (2008). Testing Baumol: Institutional quality and the productivity of entrepreneurship. Business Venturing, 23(6), 641-655. https://doi.org/10.1016/j.jbusvent.2008.01.004

Soumaré, I., \& Tchana Tchana, F. (2015). Causality between FDI and financial market development: Evidence from emerging markets. The World Bank Economic Review, 29(suppl_1), S205-S216.

Tabellini, G. (2010). Culture and institutions: Economic development in the regions of Europe. Journal of the European Economic Association, 8(4), 677-716. https://doi.org/10.1111/j.1542-4774.2010. tb00537.x

Tebaldi, E., \& Elmslie, B. (2013). Does institutional quality impact innovation? Evidence from crosscountry patent grant data. Applied Economics, 45(7), 887-900. https://doi.org/10.1080/00036846. 2011.613777

Varsakelis, N. C. (2006). Education, political institutions and innovative activity: A cross-country empirical investigation. Research Policy, 35(7), 1083-1090. https://doi.org/10.1016/j.respol.2006.06.002

Waguespack, D. M., Birnir, J. K., \& Schroeder, J. (2005). Technological development and political stability: Patenting in Latin America and the Caribbean. Research Policy, 34(10), 1570-1590. https://doi. org/10.1016/j.respol.2005.07.006

Wilde, J. (2000), Identification of multiple equation probit models with endogenous dummy regressors. Economic Letters, 69, 309-312.

Publisher's Note Springer Nature remains neutral with regard to jurisdictional claims in published maps and institutional affiliations. 